\title{
ANÁLISE PROSPECTIVA PARA OURO NAS REGIÕES OURO ROXO-CANTAGALO E CHICO TORRES, PROVÍNCIA MINERAL DO TAPAJÓS
}

\author{
Thais Andressa Carrino ${ }^{1}$, Adalene Moreira Silva ${ }^{1}$, \\ Nilson Francisquini Botelho ${ }^{1}$ e Alexandre Augusto Cardoso da Silva² \\ Recebido em 13 maio, 2010 / Aceito em 19 janeiro, 2011 \\ Received on May 13, 2010 / Accepted on January 19, 2011
}

\begin{abstract}
Spatial modeling (fuzzy logic) was used to predict key areas for gold exploration in the Tapajós Mineral Province (Brazilian Amazon), specifically in the regions here named Ouro Roxo-Cantagalo and Chico Torres. The data used were regional airborne geophysical and SAR-R99B data. The airborne geophysical data processing allowed the generation of evidence layers for modeling approaches. The best evidences in current models were anomalous potassium, F parameter, radioelement ratios, radioelement normalization, and amplitude of the analytical signal of the magnetic anomalous field. The SAR images were used in the photointerpretation stage. In the case of regions of the Ouro Roxo-Cantagalo and Chico Torres shear zones, geophysical images and interpretations (when necessary) were used to application of fuzzy logic, and the gold locations were used to evaluate the quality of the modeling results. The main contributions of this research include the observation of potential gamma-ray spectrometry signatures, the refining interpretation of the digital data, and improving the information of the current geological maps. The prospective Ouro Roxo-Cantagalo and Chico Torres modeling results using the conceptual fuzzy logic method exemplify the generation of regional exploration models for the cartography and selection of gold potential areas. This methodology can be extended to others regions of the Tapajós Mineral Province using airborne geophysical data current available by CPRM and the SAR images of the Centro Técnico Operacional do Sistema de Proteção da Amazônia (CENSIPAM).
\end{abstract}

Keywords: fuzzy logic, predictive maps, greenfield areas.

RESUMO. Modelagem espacial (lógica fuzzy) foi empregada para a previsão de áreas potenciais à exploração aurífera na Província Mineral do Tapajós (PMT Amazônia brasileira), especificamente nas regiões aqui denominadas Ouro Roxo-Cantagalo e Chico Torres. Os dados utilizados compreendem os aerogeofísicos e de imagens SAR-R99B. 0 processamento dos dados aerogeofísicos permitiu a geração de imagens como as do potássio anômalo, parâmetro F, razões e normalização de radioelementos e a amplitude do sinal analítico do campo magnético anômalo, enquanto que imagens SAR foram empregadas para a etapa de fotointerpretação. A partir da geração de modelos hipotéticos para mineralizações de ouro nas regiões das zonas de cisalhamento Ouro Roxo-Cantagalo e Chico Torres, imagens geofísicas e interpretações, quando convenientes, foram selecionadas para a geração de modelos prospectivos por meio da lógica fuzzy, enquanto que as ocorrências de ouro já conhecidas foram usadas para avaliar a qualidade dos resultados modelados. As principais contribuições desta pesquisa incluem a observação de assinaturas gamaespectrométricas potenciais, um refinamento interpretativo dos dados digitais e melhoramento de informações apresentadas nos mapas geológicos atuais. Os resultados das modelagens prospectivas para as regiões Ouro Roxo-Cantagalo e Chico Torres a partir da lógica fuzzy exemplificam a geração de modelos exploratórios regionais para a cartografia e seleção de áreas com potencial para mineralizações de ouro, podendo esta metodologia ser estendida a outras regiõos da PMT, utilizando-se os dados aerogeofísicos atualmente disponíveis pelo Serviço Geológico do Brasil e as imagens SAR do Centro Técnico Operacional do Sistema de Proteção da Amazônia (CENSIPAM).

Palavras-chave: lógica fuzzy, mapas previsionais, áreas do tipo greenfield.

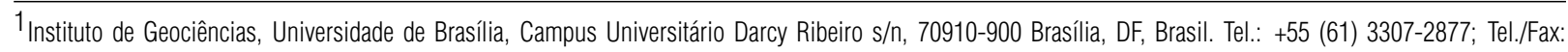
+55 (61) 3340-4759 - E-mails: thais.carrino@gmail.com; adalene@unb.br; nilsonfb@unb.br

${ }^{2}$ Centro de Pesquisa e Desenvolvimento - CENPES, Petrobras, Av. Horácio de Macedo, 950, Cidade Universitária, Ilha do Fundão, 21941-915 Rio de Janeiro, RJ, Brasil. Tel.: +55 (21) 3865-7573 - E-mail: alexandreaugusto@petrobras.com.br
} 


\section{INTRODUÇÃo}

A Província Mineral do Tapajós (PMT), considerada a maior província produtora de ouro do país segundo Dardenne \& Schobbenhaus (2001), caracteriza-se como uma região de grande potencial econômico, mas ainda carente de estudos geológicos em boa escala para a prospecção. Para os seus $90.000 \mathrm{~km}^{2}$ de área, o conhecimento geológico consiste, no geral, em cartas regionais em escalas 1:250.000 (Almeida et al., 2000; Bahia \& Quadros, 2000; Ferreira et al., 2000; Klein \& Vasquez, 2000; Vasquez \& Klein, 2000) e 1:500.000 (Klein et al., 2001). Além disso, há uma grande discussão acerca da caracterização metalogenética de vários prospectos auríferos, assim como das épocas de mineralização existentes nesta província. Como exemplo, Coutinho et al. (2000) estabelecem duas épocas mineralizadoras em 1,96 Ga e 1,88 Ga; Santos et al. (2001) propõem a idade máxima para os depósitos do tipo intrusion related em 1,862 Ga; Klein et al. (2002) enfatizam um evento mineralizador entre aproximadamente 1,97 e 1,95 Ga na porção sudeste da PMT (área do Prospecto Patinhas).

No geral, pode-se classificar a PMT como uma imensa região do tipo greenfield, ou seja, marcada por grande potencial econômico em contrapartida ao escasso conhecimento geológico e metalogenético atual.

A exploração de ouro, nos últimos cinquenta anos, foi realizada intensamente em aluviões, elúvios e colúvios por meios rudimentares em garimpos (Peregovich et al., 2008). Mais recentemente, ocorrências primárias próximas às secundárias passaram a ser mapeadas utilizando-se dados indiretos e de mapeamento geológico. Dados anteriores à crise econômica que afetou 0 setor mineral brasileiro no final de 2008 indicavam que cerca de 40.000 garimpeiros exerciam a função (Rodrigues et al., 2008), e aproximadamente doze companhias estavam ativas explorando a província (Peregovich et al., 2008). Já a produção total de ouro desde 1958 foi estimada em 500 toneladas (Rodrigues et al., 2008), mas pode compreender um número maior, em função da exploração não fiscalizada deste metal.

As mineralizações auríferas estão associadas, principalmente, com zonas de cisalhamento e intrusões graníticas, havendo associações frequentes com diques máficos e de andesitos, além de depósitos classificados como do tipo epitermal e supergênicos (Faraco et al., 1997; Dreher et al., 1998; Martini, 1998; Almeida et al., 2001; Klein et al., 2001, 2008; Santos et al., 2001; Juliani et al., 2002, 2005, 2008; Peregovich et al., 2008).

Alguns trabalhos utilizando dados de radar de abertura sintética e aerogeofísicos abrangendo o domínio da PMT demonstraram bons resultados na discriminação espacial de al- vos geológicos com potencialidade para mineralizações auríferas assim como possíveis assinaturas geofísicas associadas com alterações hidrotermais (e.g., Pedroso et al., 2001; Silva, 2003; Silva et al., 2007). Entretanto, tais trabalhos não suprem toda a magnitude da província, fato que gera um grande desafio a fim da caracterização dos diferentes jazimentos encontrados nesta vasta região, uma vez que o nível de conhecimento em cada um destes é dependente do maior ou menor grau exploratório dos prospectos.

Frente a estas perspectivas, o objetivo deste trabalho compreende a investigação das recentes imagens de radar de abertura sintética (SAR) da plataforma aérea R99B, além de dados aerogeofísicos regionais na caracterização de duas importantes regiões auríferas da PMT, a fim de contribuir para a definição de novos alvos potenciais para a exploração aurífera. Estas áreas, aqui denominadas Ouro Roxo-Cantagalo e Chico Torres (Fig. 1), serão abordadas também pelo fato da disponibilidade dos dados multifonte acima citados.

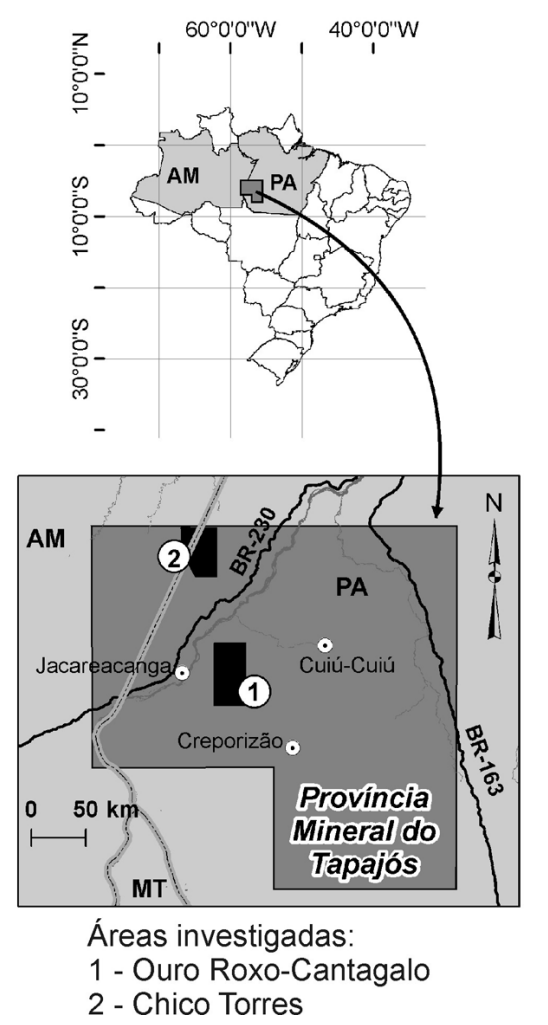

Figura 1 - Localização da Província Mineral do Tapajós nos estados do Amazonas e Pará e inserção das áreas Ouro Roxo-Cantagalo e Chico Torres, ambas focadas neste artigo.

\section{CONTEXTO GEOLÓGICO DA PROVÍNCIA MINERAL DO TAPAJÓS}

A PMT está inserida na porção centro-sul do Cráton Amazônico, especificamente no segmento sul da Província Geocronológica 
Tapajós-Parima (2,03-1,88 Ga), definida por Santos et al. (2000, 2006).

0 contexto geológico dessa província é caracterizado por uma grande produção de crosta continental, principalmente entre 2,00 Ga e 1,96 Ga (ambiente compressivo) e entre 1,90 e 1,87 Ga (ambiente distensivo), envolvendo eventos como acresção e encurtamento crustal relacionados à amalgamação de um arco magmático a um proto-cráton arqueano (atual região de Carajás) (Klein et al., 2001).

A confirmação de arcos magmáticos existentes no Tapajós ainda é motivo de discussão: Klein et al. (2001) e Vasquez et al. (2002) atribuem a existência de um único arco (Cuiú-Cuiú), enquanto Santos et al. $(2000,2001,2004)$ defendem a ocorrência de outros (Tropas, Creporizão, Parauari, Jamanxim, além do CuiúCuiú).

A possível existência de todos os arcos propostos por Santos et al. (2000) foi questionada por Vasquez et al. (2002). Estes autores mostram uma incompatibilidade para a formação do arco Tropas num período caracterizado pelo regime extensional em todo o Cráton Amazônico, ao invés de um regime compressional, além de citarem a ausência de uma caracterização mais completa desse possível arco e das bacias associadas. Adicionalmente, as considerações de Klein et al. (2001) e Vasquez et al. (2002) apresentam-se mais compatíveis com as interpretações geológico-geofísicas realizadas por Silva (2003), que defende a existência de apenas um arco de ilha colidindo com uma área cratônica formando granitos colisionais do Complexo Cuiú-Cuiú, granitos sin a tardi-colisionais da Suíte Intrusiva Creporizão, granitos pós-colisionais da Suíte Intrusiva Parauari e granitos pós-colisionais a anorogênicos da Suíte Intrusiva Maloquinha.

\section{Principais unidades hospedeiras de ouro}

As principais unidades litoestratigráficas da PMT hospedeiras das mineralizações primárias de ouro, e que caracterizam as duas áreas apresentadas neste artigo (Fig. 2), são descritas mais detalhadamente abaixo.

0 Complexo Cuiú-Cuiú abrange rochas metamórficas de médio a alto grau (gnaisses ortoderivados) e plutônicas associadas (granitos pouco deformados, leucogranitos e granitos alasquíticos). Outros litotipos mais raros correspondem a migmatitos, dioritos, anfibolitos e xenólitos de metapiroxenitos (Klein et al., 2001) (Fig. 2). As rochas desta unidade são caracterizadas por deformação rúptil e dúctil. Datação de zircão de um tonalito pelo método U-Pb resultou na idade de $2011 \pm 23 \mathrm{Ma}$ (Santos et al., 2000). Santos et al. (2001) listaram cinco idades adicionais pelo método U-Pb para o Complexo Cuiú-Cuiú, que equivalem a um intervalo de 2040 a $1998 \mathrm{Ma}$, considerando-se a incerteza de cada análise.

A Suíte Intrusiva Parauari compreende uma associação de rochas graníticas pertencentes à série cálci-alcalina de médio a alto $\mathrm{K}$, metaluminosas, às vezes peraluminosas, possuindo características de arco vulcânico (Klein et al., 2001). Abrange rochas como (biotita) granodiorito, (clinopiroxênio)-biotita-hornblenda granodiorito e (biotita) monzogranito, raros tonalito e biotita sienogranitos (Klein et al., 2001) (Fig. 2). A datação de zircões do monzogranito Parauari pelo método de U-Pb gerou idade de 1879 \pm 2 Ma (Santos et al., 2004).

0 Supergrupo Uatumã abrange litotipos do Grupo Iriri e da Suíte Intrusiva Maloquinha que consistem, respectivamente, em rochas vulcânicas e plutônicas pós-orogênicas a anorogênicas (Almeida et al., 2000; Ferreira et al., 2000; Klein et al., 2001) (Fig. 2).

0 Grupo Iriri é subdividido em duas formações: a Salustiano, composta por rochas vulcânicas ácidas (riolitos, riodacitos, dacitos), e a Aruri, caracterizada por rochas vulcanoclásticas (tufos, ignimbritos, brechas vulcânicas). Zircões de riodacito do Grupo Iriri foram datados por meio do método U-Pb (SHRIMP), produzindo-se uma idade de $1870 \pm 8 \mathrm{Ma}$ (Santos et al., 2001).

A Suíte Intrusiva Maloquinha abrange granitos batolíticos que são controlados por falhamentos NNW-SSE (Fig. 2). Nas áreas de estudo ocorre a fácies à biotita, compreendendo sienogranito, monzogranito e mais raramente álcali-feldspato granito com biotita e típica coloração rósea-avermelhada (Klein et al., 2001). Zircões de rochas graníticas desta suíte foram datados por Santos et al. (2001) pelo método U-Pb (SHRIMP), resultando nas seguintes idades: $1877 \pm 12 \mathrm{Ma}, 1874 \pm 7 \mathrm{Ma}, 1871 \pm 8 \mathrm{Ma}$ e $1864 \pm 18$ Ma.

\section{REGIÕES INVESTIGADAS DO TAPAJÓS Ouro Roxo-Cantagalo}

Esta região está inserida no trend aurífero Santa Isabel-0uro Roxo (Coutinho, 2008), e as principais unidades litoestratigráficas presentes compreendem o Complexo Cuiú-Cuiú, a Suíte Intrusiva Parauari, o Grupo Iriri (Formação Salustiano), a Suíte Intrusiva Maloquinha e aluviões (Klein et al., 2001) (Fig. 2(a)).

A principal zona de cisalhamento, Ouro Roxo-Cantagalo, também já denominada de Centrinho-Cantagalo (Santos et al., 2001) e São José (Klein et al., 2001), caracteriza-se por ter direção aproximada N-S e mergulho de médio ângulo (Santos et al., 2001) (Fig. 2(a)). Há um forte controle estrutural das mineralizações, com depósitos distribuídos principalmente a leste da principal zona de cisalhamento (Klein et al., 2001; Santos et al., 2001). Estas mineralizações estão associadas com zonas de cisalhamento 

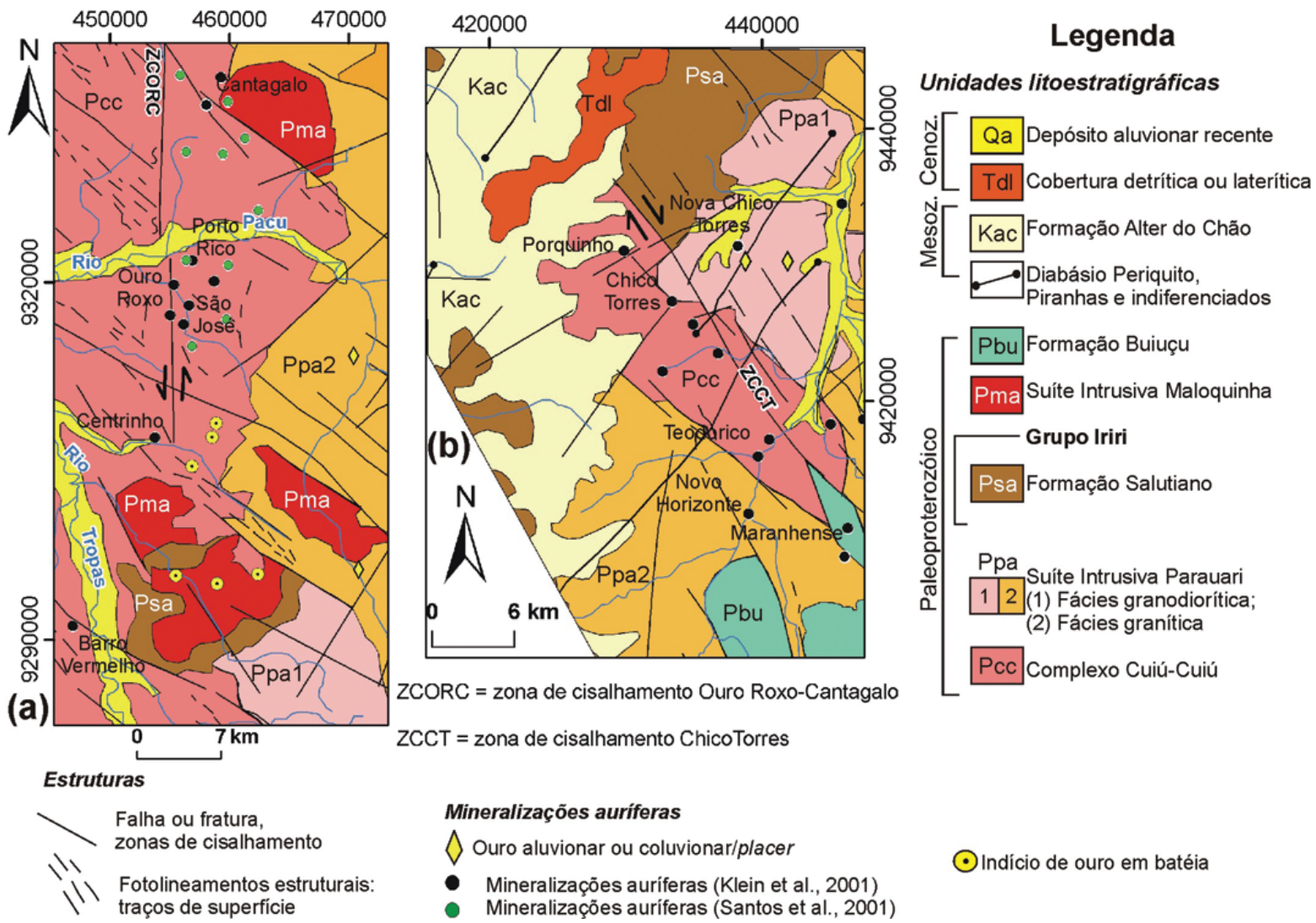

○Indício de ouro em batéia

Figura 2 - Mapas geológicos das áreas em estudo: (a) região da zona de cisalhamento Ouro Roxo-Cantagalo (Klein et al., 2001); (b) região Chico Torres (Klein et al., 2001).

secundárias com cerca de $3 \mathrm{~km}$ de extensão e entre as direções N10E e N30E. As rochas hospedeiras são pertencentes ao Complexo Cuiú-Cuiú (Klein et al., 2001; Veloso et al., 2008) ou à Suíte Intrusiva Tropas (tonalito, granodiorito, com xenólitos de basalto e de andesito derivados do arco Cuiú-Cuiú e da Suíte Intrusiva Creporizão), conforme proposto por Santos et al. (2001).

Segundo Klein et al. (2001), a região é caracterizada por alto potencial aurífero, marcado por veios de quartzo conjugados, lenticularizados e boudinados, encaixados em ortognaisses do Complexo Cuiú-Cuiú, à leste da zona de cisalhamento Ouro Roxo-Cantagalo, e contendo ouro e sulfetos. À norte, há alta frequência de ocorrências primárias de ouro em veios de quartzo simples, extensionais, encaixados em granitos da Suíte Parauari.

Santos et al. (2001), analisando o prospecto Ouro Roxo, encontraram pirita disseminada em veios de quartzo, além da forte correlação entre 0 conteúdo de pirita e a abundância de ouro. Além disso, foram constatadas ocorrências de ouro visível como em pirita e na sua forma livre. Veloso et al. (2008) também estudaram o prospecto Ouro Roxo e concluíram que a mineralização é compatível com um depósito do tipo orogênico, em concor- dância a Santos et al. (2001). Segundo Veloso et al. (2008), a zona de cisalhamento transcorrente Ouro Roxo-Cantagalo afetou rochas graníticas e gerou protomilonito e milonito intercalados com zonas de brecha mais restritas. Além da pirita, observa-se a ocorrência de calcopirita, esfalerita e bismutita. As principais alterações hidrotermais consistem na sericitização/fengitização, silicificação, sulfetação, cloritização e carbonatação.

Cristais prismáticos de hornblenda e lamelas de biotita encontram-se intensamente substituídos por clorita e carbonato e associados com titanita e magnetita. Há também frequentes xenólitos centimétricos a métricos de basaltos e andesitos alterados hidrotermalmente em clorita, epidoto, albita, leucoxênio e pirita (Santos et al., 2001).

Na região do prospecto São José, Coutinho (2008) relata a presença de veios de quartzo orientados na direção N-S e N25E, intercalados no granito da Suíte Intrusiva Parauari. A mineralogia mostra pirita, calcopirita, calcosita, covelita, goethita e limonita.

Análises de dados aerogeofísicos regionais revelaram altos valores de $\mathrm{K}$ associados com áreas mineralizadas, como foi reconhecido por Klein et al. (2001), por meio de altos valores das 
razões de K/eTh e K/eU, e reforçado por Pedroso et al. (2001), Silva (2003) e Silva et al. (2007).

\section{Chico Torres}

Esta área localiza-se na porção noroeste da PMT (Fig. 2(b)), e insere-se no trend aurífero São Jorge-Chico Torres, de direção NW-SE (Coutinho, 2008).

As unidades mais antigas dessa região incluem o Complexo Cuiú-Cuiú, rochas graníticas das suítes intrusivas Parauari e Maloquinha, diabásio e monzogabro da Suíte Intrusiva Ingarana, rochas vulcânicas ácidas (formações Salustiano e Aruri), arenitos da Formação Buiuçu, além da sedimentação mais recente representada pela Formação Alter do Chão, coberturas detríticas ou lateríticas e aluviões (Fig. 2(b)).

A região é caracterizada por mineralizações auríferas em veios de quartzo sulfetados que se concentram em estruturas secundárias de direção NE-SW e NW-SE e mergulhos verticais e subverticais ao longo da zona de cisalhamento Chico Torres. Essa zona de direção NW-SE é parte de um sistema de falhas paleoproterozóicas da PMT e caracteriza-se por ser de transcorrência dextral (Fig. 2(b)).

Rochas hospedeiras de mineralizações auriferas incluem ortognaisses do Complexo Cuiú-Cuiú (prospecto Porquinho, e algumas lavras do Chico Torres), rochas graníticas da Suíte Intrusiva Parauari (prospectos Chico Torres, Nova Chico Torres, Cara Preta, Maranhense) e rochas vulcânicas do Grupo Iriri (lavra Melechete do prospecto Chico Torres), que se encontram hidrotermalizadas em diferentes intensidades nos domínios da zona de cisalhamento. As principais alterações hidrotermais presentes nos prospectos desta região compreendem a sulfetação, cloritização, sericitização, silicificação e epidotização (Klein et al., 2001).

Para Santos et al. (2001), o Prospecto Chico Torres está classificado como um depósito do tipo intrusion related, tendo sido observados veios de quartzo-pirita-ouro bandados, além de constatado alto grau de minério ( $\sim 30 \mathrm{~g} / \mathrm{t} \mathrm{Au})$.

\section{MATERIAIS}

\section{Imagens SAR-R99B}

Os dados de radar de abertura sintética da plataforma R99B, referentes à missão Terra do Meio Oeste de 2006 que recobriu parte dos estados do Amazonas e Pará, compreendem duas faixas de voo imageadas em banda L, polarização HH, com resolução espacial em alcance e azimute de $18 \mathrm{~m}$ e tamanho de pixe/ de $15 \mathrm{~m}$. A altura de aquisição destes dados aerotransportados equivaleu a 35.000 pés e foram empregados 8 looks e ângulo de incidência variando de $45^{\circ}$ a $81,10^{\circ}$ (com visada para oeste). Estes dados foram cedidos pelo Centro Técnico Operacional do Sistema de
Proteção da Amazônia (CENSIPAM) de Belém em formato 8 bits.

\section{Aerolevantamento geofísico}

Os dados regionais do aerolevantamento Bloco 1 - Província Aurífera do Tapajós foram obtidos pela empresa Lasa Engenharia e Prospecção S.A., contratante da CPRM, entre os meses de junho e novembro de 1997. Consistem em dados magnetométricos e gamaespectrométricos com espaçamento das linhas de voo (N-S) e de controle (E-W) de 1 e $13 \mathrm{~km}$, respectivamente, e foram coletados a uma altura de voo de 100 metros. As leituras do aeromagnetômetro foram realizadas a cada 5,5 m e do aerogamaespectrômetro a cada $55 \mathrm{~m}$. Os dados foram registrados a bordo da aeronave Britten-Norman, modelo BN-2A-Islander, prefixo PT-KNE, de forma digital e analógica (Lasa Engenharia e Prospecções S.A., 1998).

0 sistema aeromagnético Picodas PDAS 1000 (aquisição e compensação) foi acoplado a um sensor de vapor de césio modelo CS-12 da SCINTREX, com resolução de 0,001 nT, e montado na cauda da aeronave (Lasa Engenharia e Prospecções S.A., 1998).

Foi empregado 0 sistema Picodas, modelo PGAM, de 256 canais espectrais, para registro da radiação gama referente aos canais de $\mathrm{K}$, eU, eTh e da contagem total. 0 volume total de cristais de iodeto de sódio (Nal) ativado a tálio consistiu em 2048 polegadas cúbicas para dois conjuntos de cristais voltados para baixo e 512 polegadas cúbicas para dois conjuntos de cristais voltados para cima (Lasa Engenharia e Prospecções S.A., 1998).

\section{Dados altimétricos}

São referentes a imagens adquiridas no ano 2000 por meio do ônibus espacial Endeavour. Consistem nos dados do modelo digital de elevação do Shuttle Radar Topography Mission (SRTM), derivados da técnica de interferometria de radar e caracterizados por resolução espacial aproximada de 90 metros (Rabus et al., 2003). A imagem utilizada foi obtida sem custos através da Global Land Cover Facility, via endereço eletrônico (http://glcf.umiacs.umd.edu/index.shtml).

\section{ABORDAGEM METODOLÓGICA}

\section{Avaliação e interpretação de dados SAR}

A radiometria das imagens SAR-R99B foi homogeneizada por meio da correção do padrão de antena, que foi realizada a cada uma das faixas de voo. Em todos os casos, uma função de ordem 5 foi selecionada.

Devido ao imageamento multilook (8 looks), uma menor resolução espacial (no caso, de $18 \times 18 \mathrm{~m}$ em alcance e azimute) foi determinada para a Missão Terra do Meio Oeste. Em con- 
trapartida, esta diminuição da resolução espacial por meio das múltiplas visadas reduz os ruídos inerentes às imagens de SAR, 0 speckle. Com a análise visual das faixas de voo, não verificou-se o ruído e, por tal, não foi necessária a aplicação de filtros adaptativos para a suavização ou eliminação dos mesmos.

0 passo final compreendeu a correção geométrica. Em função da ausência de dados sobre efemérides das imagens de radar, procedeu-se com a determinação de 82 pontos de controle utilizando-se cartas topográficas em escala 1:250.00, gerando-se um erro quadrático médio de 17,58 m. Destaca-se que este procedimento também foi estendido às imagens SRTM, resultando em 89 pontos de controle e um erro quadrático médio de 4,17 m.

As imagens de radar foram utilizadas para fotointerpretação que se baseou principalmente na análise e extração visual de feições lineares e alinhamentos de drenagem, objetivando identificar os principais condicionamentos estruturais e sua possível relação tectono-evolutiva e/ou metalogenética para cada região da PMT abordada.

\section{Imagens geofísicas aéreas}

0 banco de dados geofísico aqui utilizado foi pré-processado por Silva (2003). Para os dados do Bloco 1 - Província Aurífera do Tapajós, Silva (2003) empregou o micronivelamento de Minty (1991) a partir do algoritmo criado por Blum (1999), e aplicou 0 interpolador curvatura mínima para a geração das imagens dos canais de $\mathrm{K}$, eTh, eU, da razão eTh/K e do campo magnético anômalo, todas caracterizadas por tamanho de célula de $250 \mathrm{~m}$.

\section{Gamaespectrometria}

A partir do banco de dados de Silva (2003), optou-se pela produção de imagens normalizadas do K (Kn), eTh (eThn) e eU (eUn), efetuadas a partir da divisão dos canais radiométricos pela somatória de K, eTh e eU. Posteriormente, composições coloridas foram realizadas com as imagens de Kn, eThn e eUn em RGB, respectivamente, assim como de $\mathrm{K}$, eTh, eU (RGB).

Imagens do parâmetro $\mathrm{F}$ (Efimov, 1978) e do potássio anômalo (Pires, 1995) também foram geradas. A técnica do parâmetro $F$ compreende uma tentativa de distinção de enriquecimento hidrotermal de $\mathrm{K}$ em relação à informação de background geológico, ou seja, as variações litológicas do meio. Este parâmetro consiste na relação de abundância de $\mathrm{K}$ associada à razão eTh/U e da abundância de eU relacionada à razão eTh/K.

$0 \mathrm{~K}$ anômalo (Kd) foi desenvolvido por Pires (1995) objetivando uma metodologia para realce do acumulo secundário de $\mathrm{K}$ associado com hidrotermalismo através da normalização deste radioelemento em função dos valores de eTh. Parte-se da premissa que os efeitos litológicos influenciam a concentração de eTh, havendo também uma influência similar nos canais de urânio e de potássio. Informações detalhadas a respeito desta técnica são encontradas em Pires (1995). Considerando-se a natureza estatística deste método, o processamento das imagens do $\mathrm{K}$ anômalo foi restringido a áreas marcadas pela ausência de aluviões, pois estas são caracterizadas na região da PMT por altos valores no canal do $\mathrm{K}$ e, sabidamente, não estão relacionadas com processos hidrotermais.

\section{Magnetometria}

As anomalias magnéticas apresentam uma complexidade, pois dependem não apenas da distribuição da magnetização $\mathrm{M}(\mathrm{x}, \mathrm{y}, \mathrm{z})$, como também da direção de magnetização e da direção na qual o campo é medido. Entretanto, esta complexidade é facilmente descrita no domínio Fourier (Blakely, 1996).

As transformações lineares do campo magnético anômalo aqui utilizadas equivalem a processamentos tratados, de forma genérica, como filtros passa-alta, e que foram geradas por Silva (2003). Estas transformações geralmente não definem diretamente a distribuição das fontes causativas, mas facilitam a construção de um entendimento geral da natureza das mesmas e as interpretações geológicas (Blakely, 1996).

As derivadas horizontais realçam altas frequências, produzindo picos anômalos aproximadamente localizados sobre as bordas de grandes corpos, aumentando a definição das bordas dos mesmos (Milligan \& Gunn, 1997).

A primeira derivada vertical (ou gradiente vertical) é fisicamente equivalente à medida do campo magnético simultaneamente em dois pontos verticalmente separados por uma distância $h$, subtraindo-se estes dois valores e dividindo este resultado pela separação espacial vertical dos pontos medidos (Milligan \& Gunn, 1997).

0 sinal analítico é formado pela combinação de gradientes horizontais e verticais de uma anomalia magnética (Blakely, 1996). Consiste em uma técnica independente da direção de magnetização da fonte e da direção do campo magnético terrestre. Isto implica que todos os corpos com mesma geometria possuem 0 mesmo sinal analítico. Os picos do sinal analítico são simétricos e ocorrem diretamente sobre as bordas de grandes corpos e no centro de corpos estreitos. Este tipo de filtro permite uma rápida identificação da posição das fontes e da geometria magnética (Nabighian, 1972, 1974; Roest et al., 1992; Milligan \& Gunn, 1997).

As derivadas horizontais e verticais são empregadas para 0 cálculo do sinal analítico. A partir do uso destes gradientes 
ortogonais, é possível calcular a amplitude do sinal analítico (ASA) que permite o posicionamento da mesma acima de estruturas e corpos magnéticos (Blakely, 1996).

\section{Modelagem espacial}

A previsão da distribuição espacial de depósitos minerais baseada na integração quantitativa de conjuntos de dados multifonte vem sendo crescentemente utilizada por meio da inclusão de diferentes técnicas de modelagens espaciais em Sistemas de Informações Georreferenciadas (SIGs). Exemplos podem ser verificados em Carranza \& Hale (2001), Porwal et al. (2003), Carranza (2004), Silva et al. (2005), Nykänen et al. (2007), Nykänen \& 0jala (2007), Tissari et al. (2007), Andrade (2008).

Com a finalidade de geração de mapas de favorabilidade para as regiões Ouro Roxo-Cantagalo e Chico Torres, foi utilizada a lógica fuzzy, inclusa nas técnicas dependentes de um modelo conceitual entendida por experts, também denominadas de modelagens de dados espaciais guiadas pelo conhecimento (Bonham-Carter, 1994).

\section{Lógica fuzzy}

A lógica fuzzy compreende uma técnica na qual os dados de entrada, previamente rasterizados, devem ser simplificados por meio da fuzificação, ou seja, seleção de funções de pertinência fuzzy que permitem 0 escalonamento dos dados originais em graus de variabilidade entre 0 (pertinência ausente) e 1 (pertinência total). Desta maneira, 0 uso de uma função de pertinência fuzzy (e.g., small, large, categórico), determinada de maneira subjetiva, permite a modificação do mapa em dados ordenados ou intervalares, gerando as possibilidades fuzzy (Bonham-Carter, 1994). Para 0 caso das pertinências large e small, a forma da função é escolhida por meio dos parâmetros ponto médio (mid point) que significará o valor de 0,5 de pertinência fuzzy, e espaIhamento (spread), que indica o quão rápido a pertinência fuzzy decresce do valor 1 ao 0.

Posteriormente, as possibilidades fuzzy referentes a cada mapa evidencial de entrada são combinadas por meio da escolha de operadores fuzzy, tais como: E, OU, produto algébrico, soma algébrica e fuzzy gama. Estes operadores podem ser profundamente analisados em An et al. (1991) e Bonham-Carter (1994).

0 operador OU fuzzy faz com que os valores de possibilidade fuzzy de saída sejam controlados pelos valores máximos existentes em cada mapa fuzificado. 0 operador $E$ fuzzy produz resultados para cada locação (pixe/) equivalente aos menores valores de possibilidades fuzzy dos mapas evidenciais (BonhamCarter, 1994).

0 operador produto algébrico fuzzy compreende o produ- tório das possibilidades fuzzy dos mapas de evidência, sendo o resultado final inferior ou igual à menor contribuição de valores de pertinência fuzzy dos mapas de entrada (An et al., 1991; Bonham-Carter, 1994).

0 operador soma algébrica fuzzy compreende a diferença de uma unidade em relação ao produtório das diferenças desta unidade e as possibilidades fuzzy dos mapas evidenciais a serem combinados. 0 resultado final compreende valores superiores ou iguais à maior contribuição de valores de pertinência fuzzy dos mapas de entrada (An et al., 1991; Bonham-Carter, 1994).

Com a finalidade de contrabalancear os efeitos minimizantes do produto algébrico fuzzy com os valores maximizantes do operador soma algébrica fuzzy, aplica-se o operador fuzzy gama, caracterizado pela ausência de influência tendenciosa para a seleção de alvos (Bonham-Carter, 1994) (Eq. 1):

$$
\mu_{\text {gama }}=\left(\mu_{\text {soma }}\right)^{\gamma} *\left(\mu_{\text {produto }}\right)^{1-\gamma},
$$

onde $\mu_{\text {gama }}$ é a possibilidade fuzzy resultante e $\gamma$ é o parâmetro escolhido na variação entre 0 e 1. Quando $\gamma$ é 1, a combinação fuzzy gama compreende o resultado da soma algébrica fuzzy. Quando $\gamma$ é 0 , o resultado final consiste somente na contribuição do produto algébrico fuzzy (An et al., 1991; Bonham-Carter, 1994).

\section{RESULTADOS \\ Ouro Roxo-Cantagalo}

A interpretação da imagem ternária (RGB) de $\mathrm{K}$, eTh e eU da região da zona de cisalhamento Ouro Roxo-Cantagalo (Fig. 3(a)), refinou as considerações já existentes em Klein et al. (2001), Pedroso et al. (2001), Silva (2003) e Silva et al. (2007), referentes à unidade litogeofísica hospedeira das mineralizações de ouro, caracterizada por altos valores de K. Nota-se um contato aproximado N-S onde está instalada a zona de cisalhamento Ouro Roxo-Cantagalo e que determina 0 contato tectônico a oeste desta unidade (Fig. 3(a)). Outros contatos são visíveis pelos produtos gamaespectrométricos, como 0 de direção NESW na região limítrofe com os granitos Parauari e Maloquinha (Fig. 3(a)).

Com base nestas observações e daquelas derivadas do acervo de imagens gamaespectrométricas, que inclui a razão eTh/K, parâmetro $\mathrm{F}, \mathrm{K}$ anômalo, $\mathrm{K}$ normalizado, além da imagem SARR99B, foi possível melhor caracterizar a principal área mineralizada, conforme apresentado na Figura 3(b). Observa-se que a unidade central atribuída à Suíte Tropas (cf. , Santos et al., 2001) é caracterizada, além de altos valores de K, por grande densidade de lineamentos de direção NNE-SSW com aproximadamente 3 a 


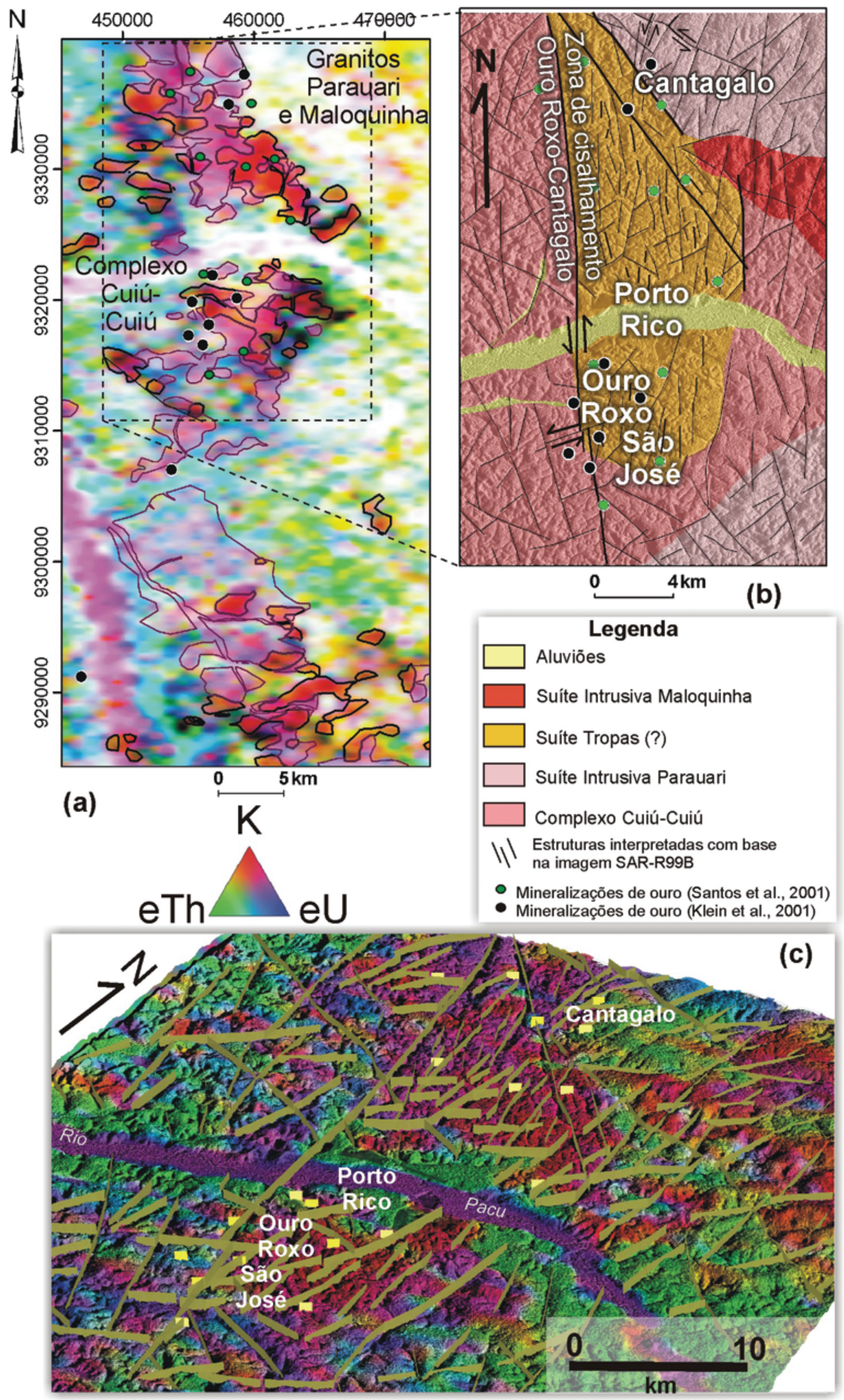

Figura 3 - Resultados gerados para a área Ouro Roxo-Cantagalo: (a) imagem de K, eTh e eU (RGB) com interpretação de unidades litogeofísicas de médio a alto K; (b) interpretação integrada de dados gamaespectrométricos e do SAR-R99B visando o reconhecimento de estruturas e unidades litogeofísicas; e (c) destaque da unidade litogeofísica de alto K normalizado caracterizada por proeminente trend estrutural NNE-SSW, assim como pela zona de cisalhamento Ouro Roxo-Cantagalo, de direção aproximada N-S. As mineralizações estão indicadas pelos polígonos em amarelo. 
5 km de extensão, e que configura o principal controle estrutural das mineralizações auríferas (ct., Santos et al., 2001). Esta mesma configuração estrutural está visualizada mais claramente na Figura 3(c), podendo-se observá-la na região central marcada por altos valores de $\mathrm{K}$ normalizado (Kn) (controle litológico) e classificá-la como a principal zona de influência metalogenética desta região.

Com relação às assinaturas magnetométricas, a região é caracterizada por altos valores da ASA, em um ambiente interpretado por Silva (2003) como relacionado ao possível registro de subducção de crosta oceânica e formação do arco magmático Cuiú-Cuiú. A Figura 4(a) apresenta esta interpretação de Silva (2003) por meio de linha tracejada branca, além das ocorrências auríferas já reconhecidas no domínio de altas amplitudes do sinal analítico. Adicionalmente, a partir da imagem da primeira derivada vertical do campo magnético anômalo, é possível identificar o domínio mineralizado como associado a relevo magnético mais rugoso (Fig. 4(b)). Lineamentos magnéticos interpretados com base na imagem da derivada vertical de primeira ordem do campo magnético anômalo estão mostrados na Figura 4(b) e relacionam-se aos trends NW-SE e NE-SW paleoproterozóicos.

As setas mostradas na Figura 4(b) revelam um contraponto existente nas bases georreferenciadas das ocorrências auríferas para a localização do prospecto Ouro Roxo. A seta azul compreende a base proveniente de Klein et al. (2001) enquanto a seta vermelha indica a localização do prospecto estudado em detalhe por Santos et al. (2001). A Figura 4(c) mostra a caracterização pontual destas duas ocorrências por meio da extração de valores dos pixe/s de imagens gamaespectrométricas e da ASA. Notase que há diferenças principalmente quanto às assinaturas de $K$ anômalo, K normalizado, parâmetro $\mathrm{F}$ e da razão K/eTh, que são maiores para a ocorrência apresentada em mapa em Santos et al. (2001). Em virtude destas diferenças, as duas bases foram empregadas de maneira individual para a validação do processamento por meio da lógica fuzzy, conforme descrito abaixo.

Todo 0 acervo de dados mencionados acima foi utilizado para a produção de mapas de favorabilidade com base na lógica fuzzy a partir da determinação de uma hipótese prospectiva. 0 modelo conceitual proposto para esta região da PMT compreende a associação da mineralização com altos valores magnéticos e de $\mathrm{K}$, além de condicionamento estrutural, visto, por exemplo, na análise da relação das ocorrências auríferas conhecidas com os temas mostrados na Figura 3, além das relações de campo descritas em alguns depósitos (Klein et al., 2001; Santos et al., 2001; Veloso et al., 2008).

Desta maneira, foram selecionados os seguintes dados para a modelagem:

(a) estruturas magnéticas, gamaespectrométricas e principalmente aquelas visualizadas por meio do SAR-R99B (Fig. $3(b, c)$ ), e caracterizadas por direção preferencial N10-30E e N-S, em analogia ao depósito Ouro Roxo (cf., Santos et al., 2001);

(b) imagem da ASA, reclassificada em 256 classes, por caracterizar a região das ocorrências atualmente conhecidas por meio de altas amplitudes. Esta caracterização está associada à ocorrência do arco Cuiú-Cuiú conforme interpretado por Silva (2003) e Silva et al. (2007);

(c) imagens gamaespectrométricas reclassificadas em 256 classes: imagens da razão de eTh/K (baixos valores caracterizando o possível hidrotermalismo), e do parâmetro $F, K$ anômalo e K normalizado, cujos maiores valores possuem maior probabilidade de associação com as mineralizações de ouro.

Definido o modelo conceitual, a lógica fuzzy foi aplicada da seguinte maneira (Fig. 5):

(a) fuzificação de todos os dados de entrada a partir da seleção das seguintes funções de pertinência fuzzy: large (para as imagens de Kn, Kd, parâmetro F e ASA), small (para a imagem de eTh/K), e categórico (para a imagem de buffers, estabelecendo pertinência de 0,95 para o intervalo de 0-250 m e 0,5 para o intervalo de 250-500 m) (Fig. 5);

(b) uso do operador E fuzzy considerando-se todos os dados gamaespectrométricos fuzificados, a fim de resultar em uma única imagem representativa, evitando-se o forte condicionamento destes dados que visam 0 realce de $\mathrm{K}$ (Fig. 5);

(c) aplicação do operador fuzzy gama considerando-se os mapas fuzificados da ASA, de buffers e o resultado do operador E fuzzy para as imagens gamaespectrométricas. Os parâmetros gama são equivalentes a 0,7 (Fig. 5(a)) e 0,9 (Fig. 5(b)).

Os dois modelos propostos, observados na Figura 5, caracterizam potencialmente a parte leste da zona de cisalhamento Ouro Roxo-Cantagalo, conforme já questionado por Klein et al. (2001). Como parte do pós-processamento da lógica fuzzy, realizou-se a validação destes resultados por meio da computação da classificação ou não das 8 ocorrências auríferas conhecidas 

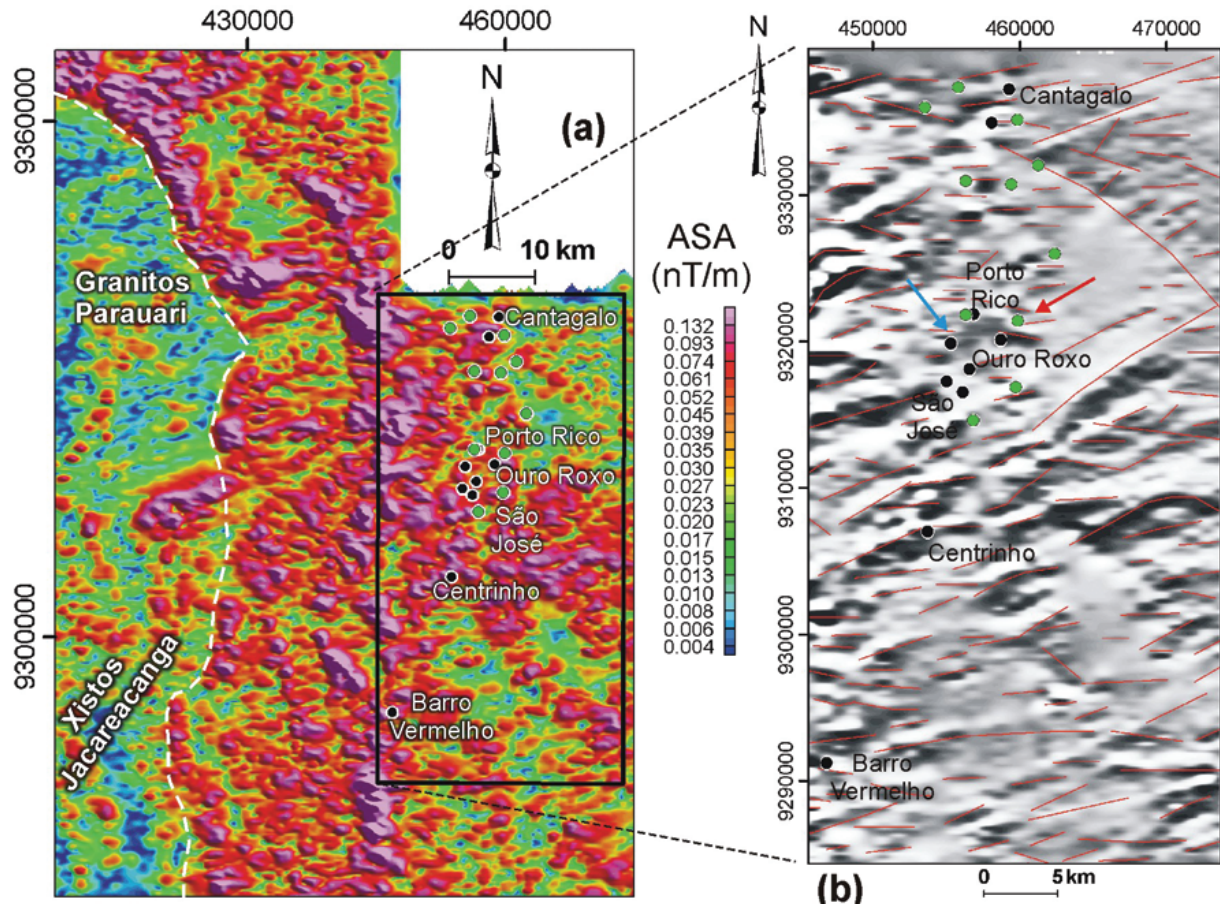

$\mathrm{DZ}$

$(\mathrm{nT} / \mathrm{m})$

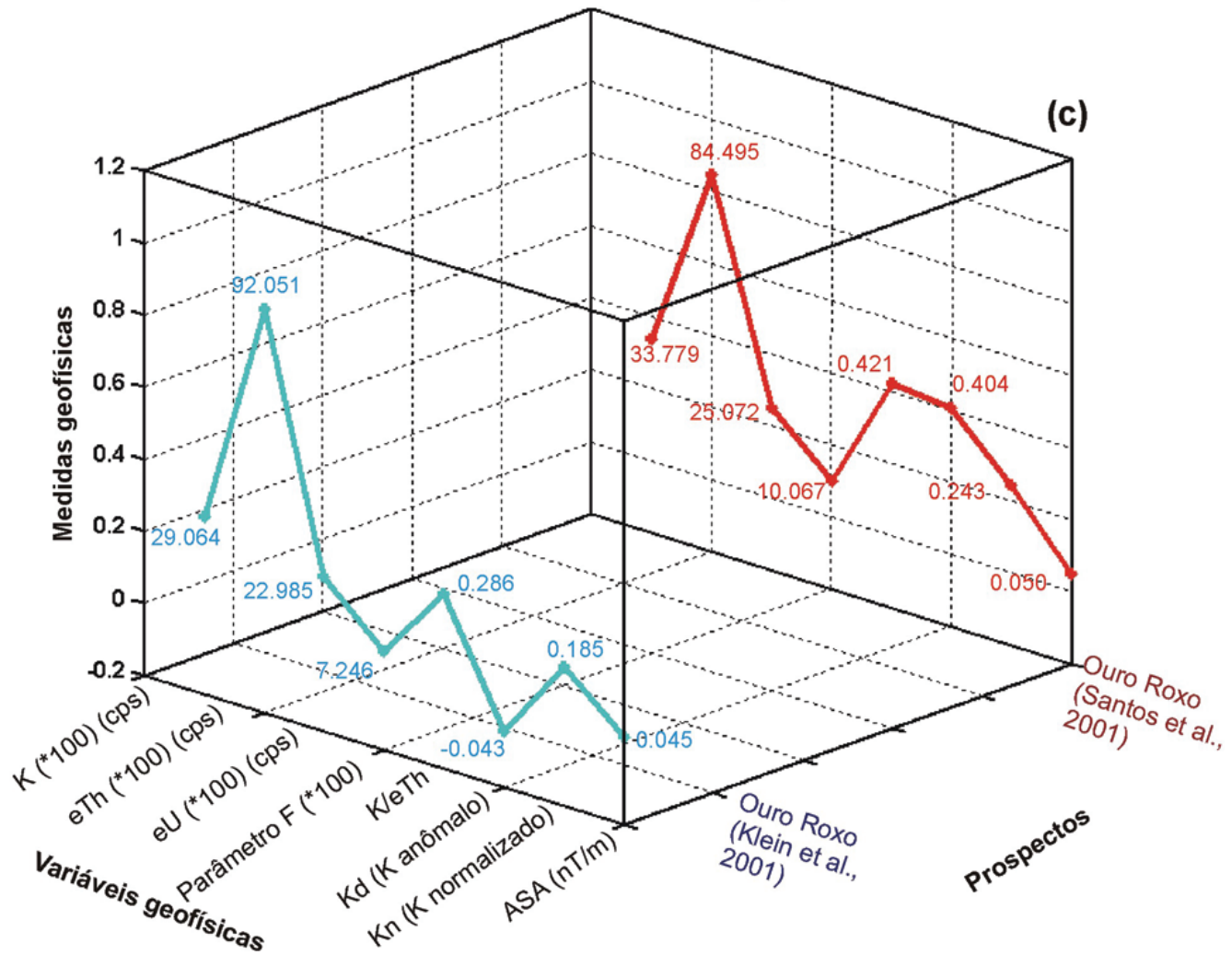

Figura 4 - Imagens magnetométricas da região Ouro Roxo-Cantagalo: (a) a ASA e a interpretação, em linha tracejada branca, de Silva (2003) e Silva et al. (2007) equivalente ao possível registro da subducção de crosta oceânica e formação do arco Cuiú-Cuiú; (b) imagem da primeira derivada vertical do campo magnético anômalo e interpretação de feições magnéticas. Seta azul indica a localização do prospecto Ouro Roxo por Klein et al. (2001), enquanto a seta vermelha refere-se ao mesmo prospecto de acordo com Santos et al. (2001). As características gamaespectrométricas e magnetométricas pontuais destas duas bases georreferenciadas do prospecto Ouro Roxo são mostradas em (c), podendo-se verificar grandes diferenças, principalmente das medidas gamaespectrométricas que realçam o $\mathrm{K}$. 


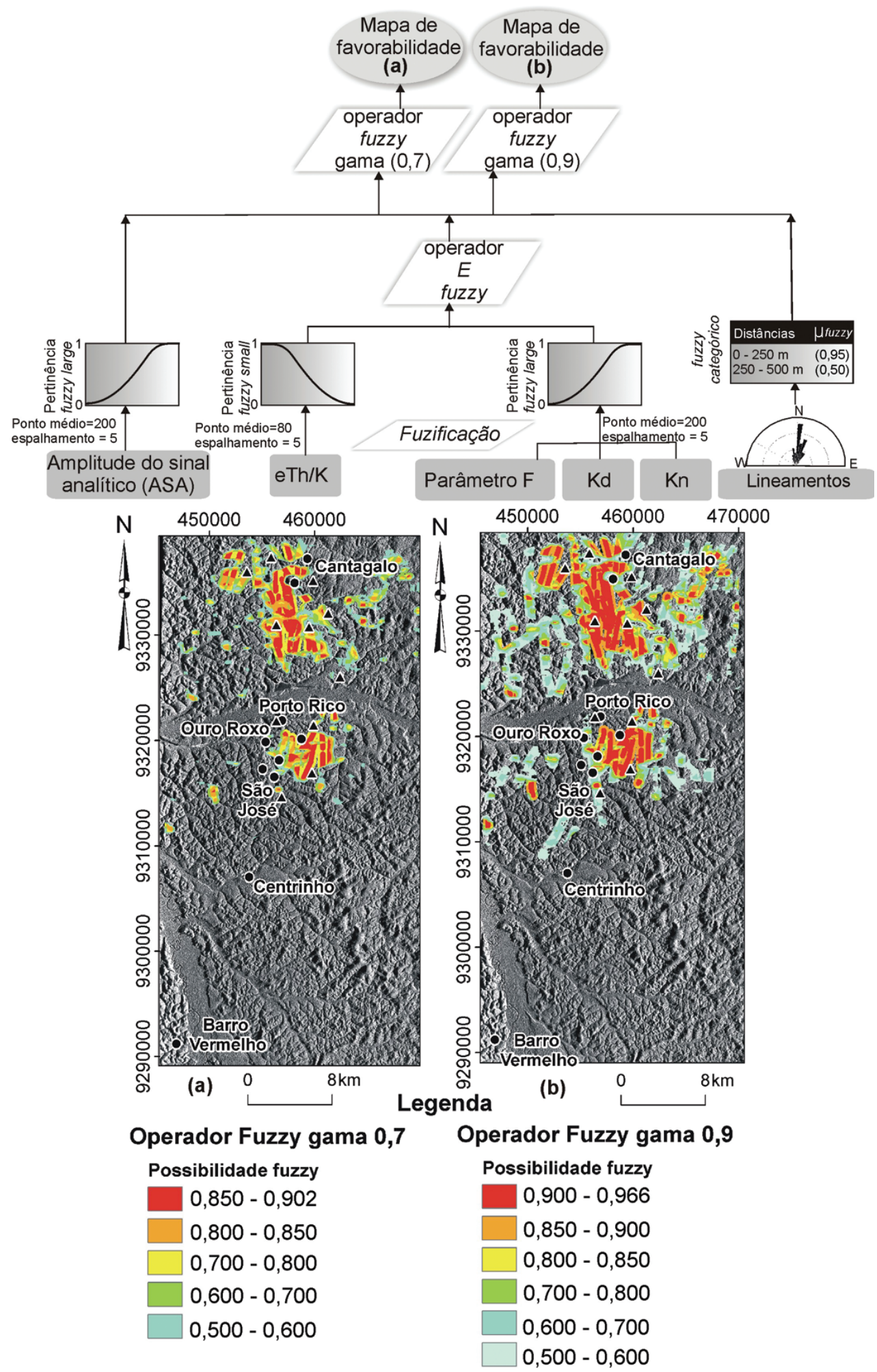

Figura 5 - Aplicação da lógica fuzzy na região Ouro Roxo-Cantagalo. Os mapas de favorabilidade aurífera foram produzidos pelos seguintes operadores fuzzy: (a) fuzzy gama $(0,7)$; (b) fuzzy gama $(0,9)$. Triângulos pretos compreendem as ocorrências de ouro identificadas em Santos et al. (2001) e círculo pretos aquelas indicadas em Klein et al. (2001). 
Tabela 1 - Quantificação de áreas classificadas por intervalos de possibilidades fuzzy resultantes da aplicação de operadores fuzzy gama na região Ouro Roxo-Cantagalo.

\begin{tabular}{|c|c|r|}
\hline \multicolumn{3}{|c|}{ Mapa de favorabilidade (operador fuzzy gama 0,7) (Fig. 5(a)) } \\
\hline Intervalo de $\mu_{\text {fuzzy }}$ & Área classificada & Área classificada acumulada \\
\hline $0,900-0,902$ & $1,1619 \mathrm{~km}^{2}$ & $1,1619 \mathrm{~km}^{2}$ \\
$0,800-0,900$ & $35,1648 \mathrm{~km}^{2}$ & $36,3267 \mathrm{~km}^{2}$ \\
$0,700-0,800$ & $24,2388 \mathrm{~km}^{2}$ & $60,5655 \mathrm{~km}^{2}$ \\
$0,600-0,700$ & $21,0474 \mathrm{~km}^{2}$ & $81,6129 \mathrm{~km}^{2}$ \\
$0,500-0,600$ & $17,4717 \mathrm{~km}^{2}$ & $\mathbf{9 9 , 0 8 4 6} \mathbf{~ k m}^{2}$ \\
$0,400-0,500$ & $20,2302 \mathrm{~km}^{2}$ & $119,3148 \mathrm{~km}^{2}$ \\
$0,300-0,400$ & $25,2441 \mathrm{~km}^{2}$ & $144,5589 \mathrm{~km}^{2}$ \\
$0,200-0,300$ & $53,2665 \mathrm{~km}^{2}$ & $197,8254 \mathrm{~km}^{2}$ \\
$0,100-0,200$ & $76,9788 \mathrm{~km}^{2}$ & $274,8042 \mathrm{~km}^{2}$ \\
$0,000-0,100$ & $52,6707 \mathrm{~km}^{2}$ & (Área total classificada) $\mathbf{3 2 7 , 4 7 4 9} \mathbf{~ k m}^{2}$ \\
\hline \hline \multicolumn{2}{|c|}{ Mapa de favorabilidade (operador fuzzy gama 0,9)(Fig. $5(\mathrm{~b}))$} \\
\hline Intervalo de $\mu$ fuzzy & Área classificada & Área classificada acumulada \\
\hline $0,900-0,966$ & $46,8207 \mathrm{~km}^{2}$ & $46,8207 \mathrm{~km}^{2}$ \\
$0,800-0,900$ & $45,7182 \mathrm{~km}^{2}$ & $92,5389 \mathrm{~km}^{2}$ \\
$0,700-0,800$ & $32,5512 \mathrm{~km}^{2}$ & $125,0901 \mathrm{~km}^{2}$ \\
$0,600-0,700$ & $50,0679 \mathrm{~km}^{2}$ & $175,1580 \mathrm{~km}^{2}$ \\
$0,500-0,600$ & $69,3954 \mathrm{~km}^{2}$ & $\mathbf{2 4 4 , 5 5 3 4} \mathbf{~ k m}^{2}$ \\
$0,400-0,500$ & $36,0495 \mathrm{~km}^{2}$ & $280,6029 \mathrm{~km}^{2}$ \\
$0,300-0,400$ & $21,2625 \mathrm{~km}^{2}$ & $301,8654 \mathrm{~km}^{2}$ \\
$0,200-0,300$ & $14,1696 \mathrm{~km}^{2}$ & $316,0350 \mathrm{~km}^{2}$ \\
$0,100-0,200$ & $5,1246 \mathrm{~km}^{2}$ & $321,1596 \mathrm{~km}^{2}$ \\
$0,000-0,100$ & $6,3153 \mathrm{~km}^{2}$ & (Área total classificada) $\mathbf{3 2 7 , 4 7 4 9} \mathbf{~ k m}^{2}$ \\
\hline
\end{tabular}

por Klein et al. (2001) na principal área mineralizada para possibilidade fuzzy de até 0,5 (corte estabelecido), e análise quantitativa das áreas classificadas por intervalos de possibilidades fuzzy, incluindo-se as áreas acumuladas totais (Tab. 1).

Dessa forma, para o mapa potencial gerado pelo operador fuzzy gama 0,7 (Fig. 5(a)), houve a validação de 5 (62,5\%) ocorrências auríferas conhecidas na área favorável que ocupa

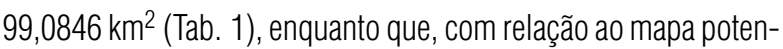
cial produzido pelo operador fuzzy gama 0,9 (Fig. 5(b)), foi realizada uma validação de 6 (75\%) ocorrências existentes na área classificada total de 244,5534 km² (Tab. 1).

Com relação aos 11 registros de ouro provenientes de Santos et al. (2001), houve uma validação de 54,44\% (6 ocorrências) e $72,73 \%$ (8 ocorrências), respectivamente, para os mapas prospectivos gerados pelos operadores fuzzy gama 0,7 e fuzzy gama 0,9 (Fig. 5).

Nota-se que os modelos prospectivos efetuados para tomada de decisão na região Ouro Roxo-Cantagalo (Fig. 5) devem ser melhorados com base em dados aerogeofísicos de maior reso- lução, pois estes permitiriam discriminar potencialmente áreas marcadas por alteração hidrotermal rica em K. Os dados com espaçamento de linhas de voo de $1 \mathrm{~km}$ aqui empregados generalizam a unidade não mapeada, mas não suprem totalmente a questão de reconhecimento hidrotermal.

\section{Chico Torres}

Esta região da PMT é caracterizada pelo trend NW-SE conforme observado pelas imagens ternárias em RGB de K, eTh, eU (Fig. 6(a)) e de Kn, eThn e eUn (Fig. 7(a)), que realçam as assinaturas chaves de médio a alto $\mathrm{K}$ e alto $\mathrm{Kn}$ ( $\mathrm{K}$ normalizado) associadas com as ocorrências de ouro cartografadas por Klein et al. (2001) e, aparentemente, com a instalação da zona de cisalhamento Chico Torres.

A unidade litogeofísica de médio a alto $\mathrm{K}$ não se associa com uma resposta dependente de uma única unidade litoestratigráfica (cf., mapa geológico da Fig. 2(b)), mas sim à interface do contato entre as três principais unidades portadoras de ouro nesta região: granitos e ortognaisses do Complexo Cuiú-Cuiú e granitos da 

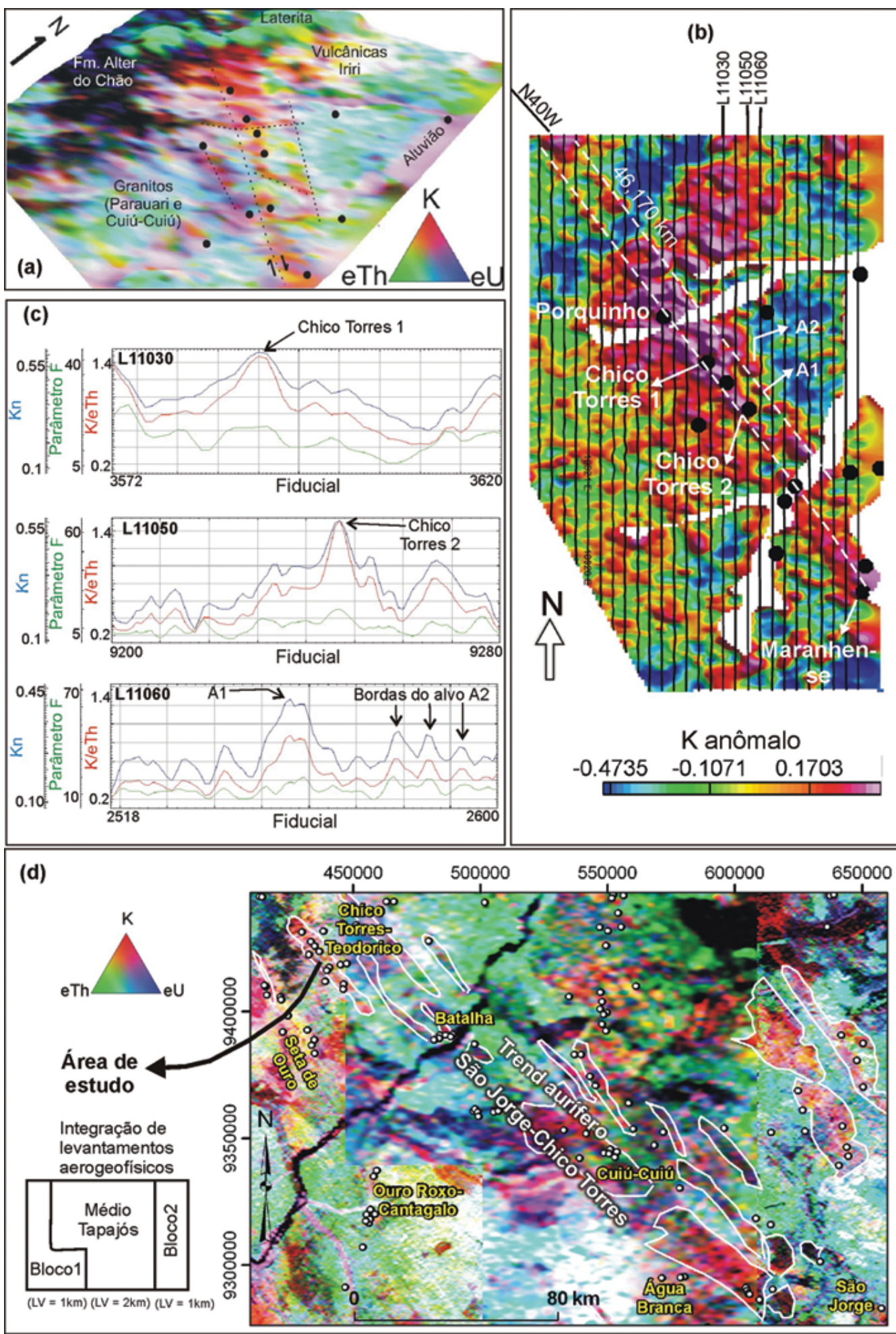

Figura 6 - Resultados referentes à região da zona de cisalhamento Chico Torres: (a) imagem ternária (RGB) de K, eTh e eU integrada com o SRTM (Shuttle Radar Topography Mission), e visualização de importante unidade litogeofísica delgada e de médio a alto K orientada na direção NW-SE; (b) imagem do Kanômalo, destacando-se 0 trend N40W; (c) perfis gamaespectrométricos, ressaltando anomalias potenciais associadas com a mineralização de ouro; e (d) inserção da região do prospecto Chico Torres no trend aurifero São Jorge-Chico Torres (Coutinho, 2008). 
Suíte Parauari, além de rochas vulcânicas do Grupo Iriri.

Destaque também é dado à imagem do K anômalo (Kd) (Fig. $6(b)$ ), a partir da qual foi possível interpretar dois trends paralelos com direção N40W, marcados por valores anômalos e com extensão de cerca de 46,170 km. Esta direção é a mesma da orientação de veios auríferos sulfetados constatados no Prospecto Chico Torres (Coutinho, 2008). Este mesmo padrão estrutural é reconhecido na imagem de radar, estando representado na Figura 7(a) pelos principais alinhamentos de drenagem interpretados.

Com a integração de dados mostrada na Figura 6(d), é possível observar que a região em estudo está inclusa no trend aurífero regional São Jorge-Chico Torres (Coutinho, 2008), assim como outros importantes distritos auríferos da PMT (e.g., Água Branca, Cuiú-Cuiú, Batalha).

A análise 1D dos dados geofísicos compreendeu outro artifício usado na região da zona de cisalhamento Chico Torres, pois tal procedimento permite averiguar assinaturas com maior resolução, já que uma medida gamaespectrométrica foi realizada a cada $55 \mathrm{~m}$. Os perfis de linhas de voo selecionados (L11030, L11050, L11060) caracterizam claramente as ocorrências de ouro desta região nos pico anômalos da razão K/eTh, Kn e parâmetro $\mathrm{F}$, a exemplo dos prospectos aqui indicados como Chico Torres 1 e 2 (Fig. 6(c)). Por sua vez, assinaturas ambíguas de alta razão K/eTh, Kn e parâmetro $\mathrm{F}$ permitiram o reconhecimento de alvos potenciais para ouro, como aqueles indicados por A1 e A2 (Fig. 6(c)).

A formulação de um modelo conceitual para a previsão aurífera na região da zona de cisalhamento Chico Torres foi realizada considerando-se: (a) as informações geradas no projeto PROMIN-Tapajós (Klein et al., 2001); (b) trabalhos que relatam típicos halos hidrotermais bem desenvolvidos (e.g., Coutinho, 2008), com alterações na qual o enriquecimento em K é marcante (e.g., fílica, com domínio de sericita); (c) forte condicionamento estrutural, principalmente com a disposição de veios auríferos em direções NW-SE. Frente a estas considerações, imagens de realce do radioelemento $\mathrm{K}$ foram selecionadas como dados de entrada para modelagem através da lógica fuzzy, a saber: eTh/K, parâmetro F, K normalizado e K anômalo.

No caso das estruturas interpretadas com base na imagem SAR-R99B (Fig. 7(a)), as assinaturas delgadas provenientes da unidade gamaespectrométrica de médio a alto $\mathrm{K}$ refletem os próprios lineamentos principais da região de estudo e que, por sua vez, correlacionam-se com as mineralizações auríferas já identificadas. Desta maneira, lineamentos gamaespectrométricos (Fig. 6(a)) ou mesmo interpretados por meio do radar (Fig. 7(a)) não foram acrescidos ao banco de dados para as modelagens, somente as imagens gamaespectrométricas supracitadas, pois estas dão representatividade à estruturação em questão. Com relação às assinaturas magnetométricas, é possível observar na Figura 7(c) a caracterização pontual das principais ocorrências de ouro desta região em função da ASA (Fig. 7(b)), assim como analisar os extensos diques de diabásio com idades entre 510 a $180 \mathrm{Ma}$ e de direção NE-SW, típicos de alguns prospectos, como o Chico Torres. Como ainda não há estudos que informem consistentemente uma possível relação destas intrusões mais recentes com uma remobilização do ouro paleoproterozóico, por exemplo, este tipo de imagem foi retirado do processo de modelagem espacial.

As unidades litoestratigráficas referentes ao mapa geológico do PROMIN-Tapajós (cf., Fig. 2(b)) também foram selecionadas para a modelagem espacial.

0 primeiro passo na aplicação da lógica fuzzy consistiu na reclassificação das imagens gamaespectrométricas para 256 classes, e posterior determinação de funções de pertinência fuzzy .

Essas funções foram estabelecidas durante 0 processo de fuzificação: às imagens de $\mathrm{K}$ normalizado, $\mathrm{K}$ anômalo, parâmetro $F$, e à imagem da razão eTh/K, estabeleceu-se uma relação de favorabilidade aos altos (função large) e baixos valores (função sma//), respectivamente, aos dois conjuntos de imagens mencionados (Fig. 8). No caso do mapa geológico, a função de pertinência fuzzy categórico foi empregada da seguinte maneira (Fig. 8): possibilidade de 0,95 à unidade Complexo Cuiú-Cuiú (onde, majoritariamente, há maior intensidade de ocorrências auríferas), 0,90 à unidade Suíte Parauari, 0,70 à unidade Grupo Iriri (Formação Salustiano), e possibilidade 0 às demais unidades onde ocorrências de ouro não são observadas (Formação Buiuçu, Formação Alter do Chão, coberturas detríticas ou lateríticas e aluviões).

0 segundo passo compreendeu a combinação dos quatro mapas de produtos gamaespectrométricos fuzificados por meio da escolha do operador E fuzzy, objetivando a redução do condicionamento destes dados (Fig. 8(a)). Posteriormente, este resultado gerado pela aplicação do operador E fuzzy toi combinado, através do operador fuzzy gama 0,7, com o mapa geológico fuzificado, resultando no mapa de favorabilidade final mostrado na Figura 8(b).

Como pós-processamento dos resultados previsionais, a Tabela 2 apresenta a quantificação das áreas classificadas segundo intervalos de possibilidades fuzzy, além das áreas acumuladas. Neste sentido, utilizando o corte de possibilidade fuzzy de 0,5, observa-se uma validação de 6 ocorrências de ouro $(66,67 \%)$ na 


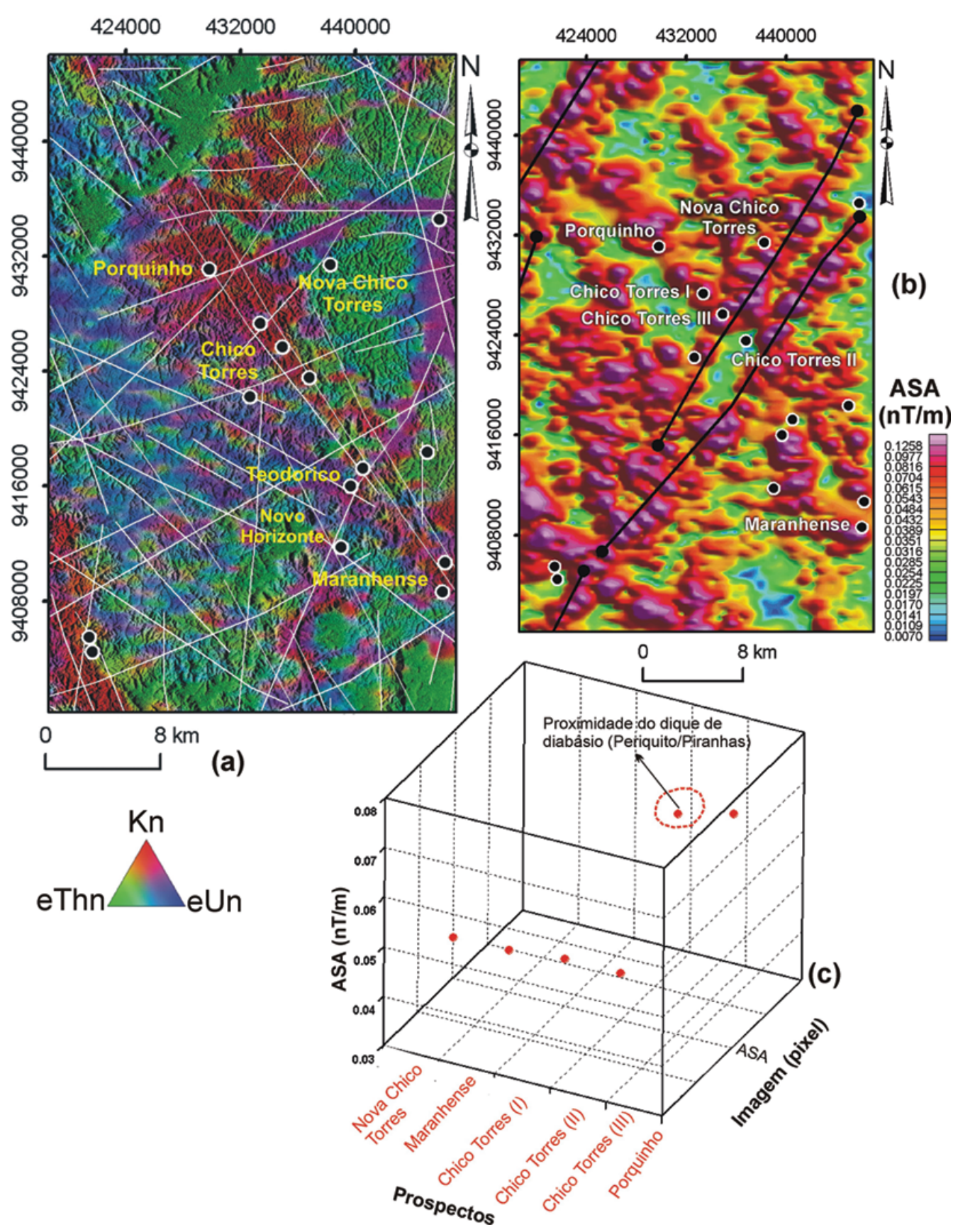

Figura 7 - Integração da imagem SAR-R99B ( $\left.\mathrm{L}_{H H}\right)$ com a da composição ternária RGB de Kn, eThn e eUn (a), incluindo os principais alinhamentos de drenagem. Imagem da amplitude do sinal analítico (ASA) integrada com ocorrências auríferas é mostrada em (b). Um gráfico tridimensional contendo as respostas extraídas de pixe/s da imagem da ASA referentes aos principais prospectos da região é apresentado em (c). Notar que altas amplitudes do sinal analítico estão associadas a alguns prospectos, e devem-se às respostas de diques máficos, os quais ainda não estão claramente definidos quanto a uma possível relação com as mineralizações auríferas.

área total de $91,5129 \mathrm{~km}^{2}$ (Tab. 2) para o mapa gerado pelo operador E fuzzy (Fig. 8(a)). No caso do mapa potencial produzido pelo operador fuzzy gama 0,7 (Fig. 8(b)), a validação foi de 7 ocorrências conhecidas $(77,78 \%$ ) e que, espacialmente, estão inseridas na área total de 246,7998 km² (Tab. 2).
Os modelos previsionais para ouro gerados com base na lógica fuzzy (Fig. 8), apesar da simplicidade, foram condizentes com o modelo conceitual estabelecido, definindo-se favorabilidades com variação ora mais 'pessimistas' (Fig. 8(a), Tab. 2) ora mais 'otimistas' (Fig. 8(b), Tab. 2) à seleção de alvos explo- 


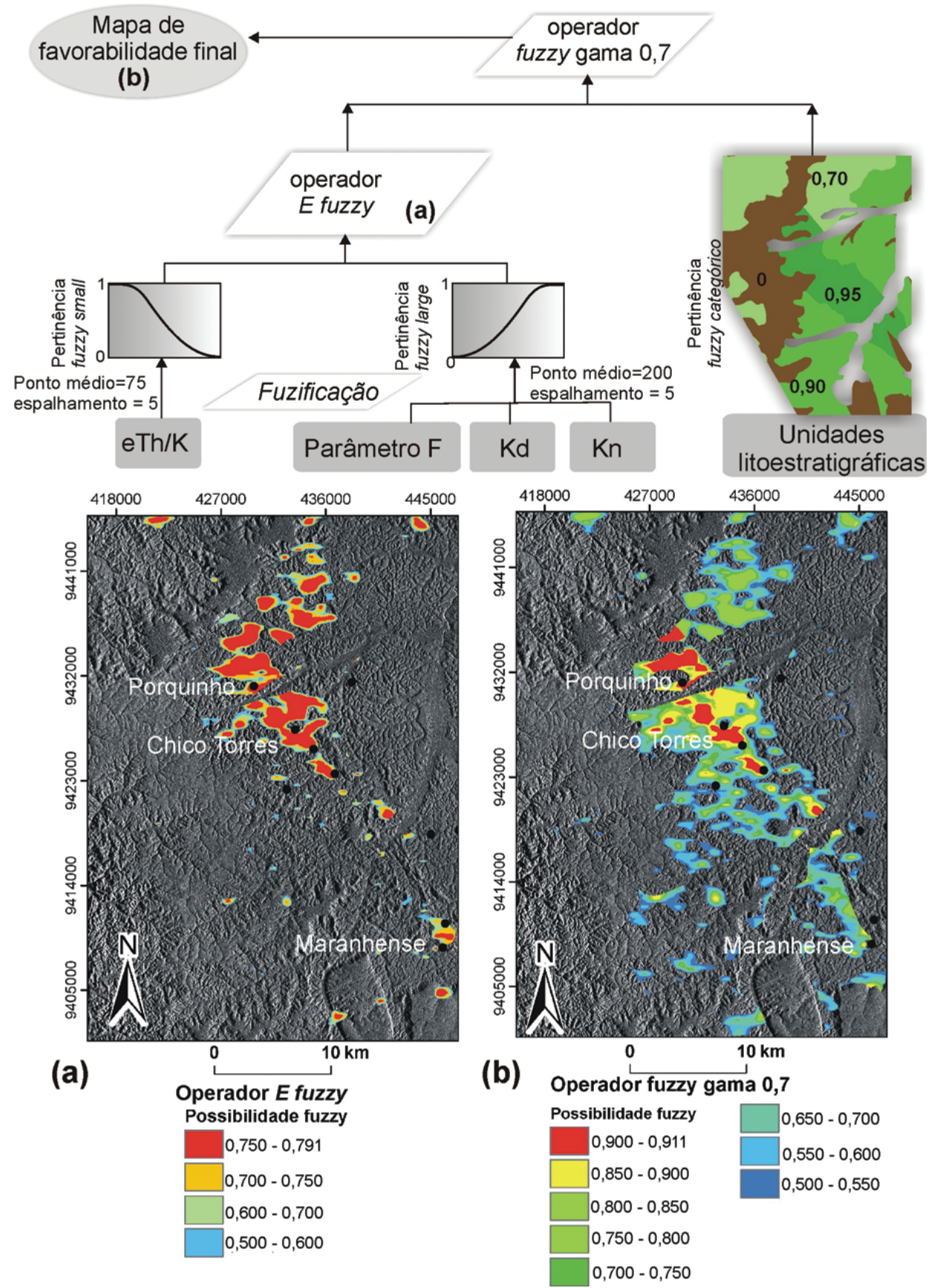

Figura 8 - Aplicação da lógica fuzzy na região da zona de cisalhamento Chico Torres. Os mapas de favorabilidade aurífera foram produzidos pelos seguintes operadores fuzzy: (a) E fuzzy; (b) fuzzy gama $(0,7)$.

ratórios. Esta seleção é dependente da natureza dos operadores fuzzy, conforme caracterizados conceitualmente (cf., An et al., 1991; Bonham-Carter, 1994). Uma maior cautela deve ser considerada na porção N-NE, na qual a existência de rochas vulcânicas ácidas do Grupo Iriri permitiu a atribuição de uma possibilidade média a alta para alvos auríferos. Esta seleção por meio da lógica fuzzy não está descartada, porém a prioridade litológica nesta área associa-se principalmente aos litotipos correspondentes ao Complexo Cuiú-Cuiú e à Suíte Intrusiva Parauari e, secundariamente, às rochas vulcânicas (cf., Fig. 2(b), Klein et al., 2001). 
Tabela 2 - Quantificação de áreas classificadas por intervalos de possibilidades fuzzy resultantes da aplicação da lógica fuzzy na região Chico Torres.

\begin{tabular}{|c|c|c|}
\hline \multicolumn{3}{|c|}{ Mapa gerado pelo operador E fuzzy (Fig. 8(a)) } \\
\hline Intervalo de $\mu_{\text {fuzzy }}$ & Área classificada & Área classificada acumulada \\
\hline $0,700-0,791$ & $56,5308 \mathrm{~km}^{2}$ & $56,5308 \mathrm{~km}^{2}$ \\
\hline $0,600-0,700$ & $20,7090 \mathrm{~km}^{2}$ & $77,2398 \mathrm{~km}^{2}$ \\
\hline $0,500-0,600$ & $14,2731 \mathrm{~km}^{2}$ & $91,5129 \mathrm{~km}^{2}$ \\
\hline $0,400-0,500$ & $23,0463 \mathrm{~km}^{2}$ & $114,5592 \mathrm{~km}^{2}$ \\
\hline $0,300-0,400$ & $47,3715 \mathrm{~km}^{2}$ & $161,9307 \mathrm{~km}^{2}$ \\
\hline $0,200-0,300$ & $75,9375 \mathrm{~km}^{2}$ & $237,8682 \mathrm{~km}^{2}$ \\
\hline $0,100-0,200$ & $147,2800 \mathrm{~km}^{2}$ & $385,1482 \mathrm{~km}^{2}$ \\
\hline $0,000-0,100$ & $650,1900 \mathrm{~km}^{2}$ & 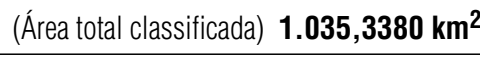 \\
\hline \multicolumn{3}{|c|}{ Mapa de favorabilidade final (operador fuzzy gama 0,7) (Fig. 8(b)) } \\
\hline Intervalo de $\mu_{\text {fuzzy }}$ & Área classificada & Área classificada acumulada \\
\hline $0,900-0,911$ & $16,6230 \mathrm{~km}^{2}$ & $16,6230 \mathrm{~km}^{2}$ \\
\hline $0,800-0,900$ & $28,7361 \mathrm{~km}^{2}$ & $45,3591 \mathrm{~km}^{2}$ \\
\hline $0,700-0,800$ & $50,5710 \mathrm{~km}^{2}$ & $95,9301 \mathrm{~km}^{2}$ \\
\hline $0,600-0,700$ & $60,8895 \mathrm{~km}^{2}$ & $156,8196 \mathrm{~km}^{2}$ \\
\hline $0,500-0,600$ & $89,9802 \mathrm{~km}^{2}$ & $246,7998 \mathrm{~km}^{2}$ \\
\hline $0,400-0,500$ & $111,4515 \mathrm{~km}^{2}$ & $358,2513 \mathrm{~km}^{2}$ \\
\hline $0,300-0,400$ & $92,4012 \mathrm{~km}^{2}$ & $450,6525 \mathrm{~km}^{2}$ \\
\hline $0,200-0,300$ & $74,5677 \mathrm{~km}^{2}$ & $525,2202 \mathrm{~km}^{2}$ \\
\hline $0,100-0,200$ & $81,9036 \mathrm{~km}^{2}$ & $607,1238 \mathrm{~km}^{2}$ \\
\hline $0,000-0,100$ & $428,2074 \mathrm{~km}^{2}$ & (Área total classificada) $1.035, \mathbf{3 3 1 3} \mathbf{k m}^{2}$ \\
\hline
\end{tabular}

\section{CONCLUSÕES}

As principais conclusões obtidas para as duas áreas abordadas da PMT incluem a definição de novas estruturas e assinaturas geofísicas chaves à exploração aurífera através de metodologia integrada de análise regional de dados aerogeofísicos e de radar de abertura sintética. Para a região Ouro Roxo-Cantagalo, a presença de unidade litogeofísica de alto Ke estruturas NNE-SSW de 3 a 5 km são interpretadas neste artigo como de grande interesse à prospecção aurífera, assim como a definição de estrutura N40W e unidade litogeofísica de médio a alto $\mathrm{K}$ com esta mesma orientação na região do Prospecto Chico Torres, e que faz parte do trend aurífero São Jorge-Chico Torres (Coutinho, 2008). Desta forma, esta metodologia prospectiva pode ser estendida a outras regiões da PMT, utilizando-se os aerolevantamentos regionais do Serviço Geológico do Brasil, as técnicas de análise 2D (grids) e $1 \mathrm{D}$ (perfis) de dados aerogeofísicos, as recentes imagens SAR do CENSIPAM, além de modelagens espaciais.

Os estudos de caso considerando as áreas Ouro Roxo-Cantagalo e Chico Torres deixam explícitos a necessidade de se criar modelos prospectivos específicos para regiões, ao invés de considerar toda a PMT. Isto porque cada setor da província é caracterizado por estruturas com diferentes direções (e.g., Prospecto Ouro Roxo - estruturas mineralizadas com direção preferencial NNE-SSW; Prospecto Chico Torres - controle estrutural das mineralizações predominante em $\sim N 40 \mathrm{~W}$ ), assim como distintos estilos das mineralizações e tipos de alterações hidrotermais.

Esse trabalho também ressalta que modelagens prospectivas dirigidas pelos dados, tais como, redes neurais, pesos de evidência entre outras, não possuem grande consistência utilizando-se 0 mesmo banco de dados selecionado neste artigo. Este fato é bem ilustrado no caso da região da zona de cisalhamento Ouro RoxoCantagalo, cujas ocorrências auríferas primárias provenientes de Klein et al. (2001) e Santos et al. (2001) não coincidem espacialmente, a exemplo do prospecto Ouro Roxo (e.g., Fig. 4(b)). Para dados mais precisos e de maior resolução, estas técnicas devem ter resultados mais coerentes.

Adicionalmente, recomenda-se o desenvolvimento de outros trabalhos envolvendo o uso de imagens SAR-R99B, visto a atual 
disponibilidade para as universidades, resolução espacial satisfatória ( $3 \mathrm{~m}, 6 \mathrm{~m}$ e $18 \mathrm{~m}$ ), e várias possibilidades de geometria de visada, objetivando o reconhecimento geológico de outras regiões da PMT ou do Cráton Amazônico como um todo. Concomitantemente a estas imagens de radar estão os novos dados geofísicos aéreos que vem sendo recentemente adquiridos pelo Serviço Geológico do Brasil. Merecem destaque os dados aerogamaespectrométricos e aeromagnetométricos do levantamento Itaituba, cuja programação pela CPRM foi prevista para 2008. Estes dados são equivalentes à área do levantamento Médio Tapajós de 1986, e caracterizados por espaçamento das linhas de voo (N-S) e de controle (E-W), respectivamente, de $500 \mathrm{~m}$ e $10 \mathrm{~km}$ (CPRM, 2008). A importância deste segmento do Tapajós equivale à instalação de um dos principais trends auríferos, o São Jorge-Chico Torres (Coutinho, 2008), abrangendo importantes prospectos como o Batalha, Cuiú-Cuiú e Água Branca.

\section{AGRADECIMENTOS}

Os autores agradecem à CPRM-DIGEOF pela cessão dos dados aerogeofísicos, ao Sr. Carlos Alberto Ribeiro de Freitas (SIPAM/ CTO-BE) pela cessão dos dados SAR-R99B e ao CT-Mineral (CNPq), processo n 555063/2006-2. T.A. Carrino agradece ao Laboratório de Geofísica Aplicada (UnB) pelo apoio técnico. A.M. Silva e N.F. Botelho agradecem ao CNPq pela bolsa de produtividade em pesquisa.

\section{REFERÊNCIAS}

ALMEIDA ME, BRITO MFL, FERREIRA AL \& MONTEIRO MAS (Orgs.). 2000. Projeto Especial Província Mineral do Tapajós (PROMIN-TAPAJÓS). Geologia e recursos minerais da Folha Vila Mamãe Anã (SB.21V-D), Estados do Amazonas e Pará. Escala 1:250.000. Brasília, CPRM, $67 \mathrm{pp}$.

ALMEIDA ME, FERREIRA AL, BRITO MFL \& MONTEIRO MAS. 2001. Evolução tectono-estrutural da Província Tapajós com base na geologia das Folhas Vila Mamãe Anã e Jacareacanga (1:250.000), região limítrofe dos Estados do Amazonas e Pará. In: REIS NJ \& MONTEIRO MAS (Coord.). Contribuições à geologia da Amazônia. Manaus, SBG-Núcleo Norte, 2: 57-114.

AN P, MOON WM \& RENCZ A. 1991. Application of fuzzy set theory to integrated mineral exploration. Canadian Journal of Exploration Geophysics, 27(1): 1-11.

ANDRADE LB. 2008. Mapeamento do potencial mineral para níquel e ouro no Cinturão Metassedimentar Nova Brasilândia - Rondônia por meio de lógica nebulosa (fuzzy) e redes neurais artificiais. Dissertação (Mestrado em Geologia) - Universidade Estadual de Campinas, Campinas-SP, $69 \mathrm{pp}$.
BAHIA RBC \& QUADROS MLES (Orgs.). 2000. Projeto Especial Província Mineral do Tapajós (PROMIN-TAPAJÓS). Geologia e recursos minerais da Folha Caracol (SB.21-X-C), Estados do Amazonas e Pará. Escala 1:250.000. Manaus, CPRM, 53 pp.

BLAKELY RJ. 1996. Potential theory in gravity \& magnetic applications. Cambridge University Press, Cambridge, 441 pp.

BLUM ML. 1999. Processamento e interpretação de dados de geofísica aérea no Brasil central e sua aplicação à geologia regional e à prospecção mineral. Tese (Doutorado em Geologia) - Universidade de Brasília, Brasilia-DF, 229 pp.

BONHAM-CARTER GF. 1994. Geographic information systems for geoscientists: modelling with GIS. Pergamon, Oxford, 398 pp.

CARRANZA EJM. 2004. Weights of evidence modeling of mineral potential: a case study using small number of prospects, Abra, Philippines. Natural Resources Research, 13(3): 173-187.

CARRANZA EJM \& HALE M. 2001. Geologically constrained fuzzy mapping of gold mineralization potential, Baguio district, Philippines. Natural Resources Research, 10(2): 125-136.

COUTINHO MGN (Ed.). 2008. Província Mineral do Tapajós: geologia, metalogenia e mapa previsional para ouro em SIG. Rio de Janeiro, CPRM, $402 \mathrm{pp}$.

COUTINHO MGN, SANTOS JOS, FALLICK AE \& LAFON JM. 2000. OrOgenic gold deposits in Tapajós Mineral Province, Amazon, Brazil. In: International Geological Congress, 31., 2000, Rio de Janeiro. Anais... Rio de Janeiro: SBG, 2000. CD-ROM.

CPRM (Companhia de Pesquisa de Recursos Minerais). 2008. Levantamentos Aerogeofísicos. Programação 2008. Disponível em:

$<$ http://www.cprm.gov.br/geo/pgb/inicio/pgb2_45.htm>. Acesso em: 25 maio 2009.

DARDENNE MA \& SCHOBBENHAUS C. 2001. Metalogênese do Brasil. Ed. UnB, Brasília-DF, p. 78-83.

DREHER AM, VLACH SRF \& MARTINI SL. 1998. Adularia associated with epithermal gold veins in the Tapajós Mineral Province, Pará State, northern Brazil. Revista Brasileira de Geociências, 28(3): 397-404.

EFIMOV AV. 1978. Multiplikativniyi pokazatel dlja vydelenija endogennych rud aerogamma-spectrometriceskim dannym. In: Metody rudnoj geofiziki. Leningrado, Naucno-proizvodstvennoje objedinenie geofizica Ed., 59-68.

FARACO MTL, CARVALHO JMA \& KLEIN EL. 1997. Carta metalogenética da Província Aurífera do Tapajós. In: COSTA ML \& ANGÉLICA RS (Coord.). Contribuições à geologia da Amazônia. Belém, SBG-Núcleo Norte, 1: 423-437.

FERREIRA AL, ALMEIDA ME, BRITO MFL \& MONTEIRO MAS (Orgs.). 2000. Projeto Especial Província Mineral do Tapajós (PROMIN-TAPAJóS). Geologia e recursos minerais da Folha Jacareacanga (SB.21-Y-B), Estados do Amazonas e Pará. Escala 1:250.000. Manaus, CPRM, 60 pp. 
JULIANI C, CORRÊA SILVA RH, MONTEIRO LVS, BETTENCOURT JS \& NUNES CMD. 2002. The Batalha Au-granite system - Tapajós Gold Province, Amazonian Craton, Brazil: hydrothermal alteration and regional implications. Precambrian Research, 119: 225-256.

JULIANI C, RYE RO, NUNES CMD, SNEE LW, CORRÊA SILVA RH, MONTEIRO LVS, BETTENCOURT JS, NEUMANN R \& ALCOVER NETO A. 2005. Paleoproterozoic high-sulfidation mineralization in the Tapajós Gold Province, Amazonian Craton, Brazil: geology, mineralogy, alunite argon age, and stable-isotope constraints. Chemical Geology, 215: 95-125.

JULIANI C, FERNANDES CMD, MAPA FB, MISAS CME \& MONTEIRO LVS. 2008. A gênese do vulcano-plutonismo Uatumã e das mineralizações de Au e de metais de base associadas nas regiões do Tapajós, Iriri e Xingu (PA). In: Simpósio de Vulcanismo e Ambientes Associados, 4., 2008, Foz do Iguaçu. Anais... Foz do Iguaçu: SBG, 2008. 10 pp.

KLEIN EL \& VASQUEZ ML (Orgs.). 2000. Projeto Especial Província Mineral do Tapajós (PROMIN-TAPAJÓS). Geologia e recursos minerais da Folha Vila Riozinho (SB.21-Z-A), Estados do Amazonas e Pará. Escala 1:250.000. Brasília, CPRM, 45 pp.

KLEIN EL, ALMEIDA ME, VASQUEZ ML, BAHIA RBC, SANTOS MLE \& FERREIRA AL. 2001. Geologia e recursos minerais da Província Mineral do Tapajós. Folhas Vila Mamãe Anã (SB.21-V-D), Jacareacanga (SB.21-Y-B), Caracol (SB.21-X-X), Vila Riozinho (SB.21-Z-A) e Rio Novo (SB.21-Z-C). Estados do Pará e Amazonas. Escala 1:500.000. Brasília, CPRM/DIEDIG/DEPAT, 81 pp.

KLEIN EL, VASQUEZ ML, ROSA-COSTA LT \& CARVALHO JMA. 2002. Geology of Paleoproterozoic gneiss- and granitoid-hosted gold mineralization in Southern Tapajós Province, Amazonian Craton, Brazil. Int. Geol. Review, 44: 544-558.

KLEIN EL, VASQUEZ ML, SOUSA CS, CARVALHO JMA \& SANTOS JR PSM. 2008. Mapa de recursos minerais do Estado do Pará: tipos, distribuição e relação com domínios tectônicos. In: Congr. Bras. Geol., 44., 2008, Curitiba. Anais... Curitiba: SBG, 2008, p. 162.

LASA ENGENHARIA E PROSPECÇÕES S.A. 1998. Projeto aerogeofísico Província Aurífera do Tapajós (Bloco l e ll): relatório final do levantamento e processamento dos dados magnetométricos e gamaespectrométricos. Volume 1. Texto técnico.

MARTINI SL. 1998. An overview of main auriferous regions of Brazil. Revista Brasileira de Geociências, 28(3): 307-314.

MILLIGAN PR \& GUNN PJ. 1997. Enhancement and presentation of airborne geophysical data. AGSO Journal of Australian Geology \& Geophysics, 17(2): 63-75.

MINTY BRS. 1991. Simple micro-levelling for aeromagnetic data. Exploration Geophysics, 22: 591-592.
NABIGHIAN MN. 1972. The analytic signal of two-dimensional magnetic bodies with polygonal cross-section: its properties and use for automated anomaly interpretation. Geophysics, 37: 507-517.

NABIGHIAN MN. 1974. Additional comments on the analytic signal of two-dimensional magnetic bodies with polygonal cross-section. Geophysics, 39: 85-92.

NYKÄNEN VM \& OJALA VJ. 2007. Spatial analysis techniques as successful mineral-potential mapping tools for orogenic gold deposits in the northern Fennoscandian shield, Finland. Natural Resources Research, 16(2): 85-92.

NYKÄNEN VM, OJALA VJ, SARAPÄÄ 0, HULKKIH H \& SARALA P. 2007. Spatial modelling techniques and data integration using GIS for target scale gold exploration in Finland. In: Proceedings of Exploration 07: Decennial International Conference on Mineral Exploration, 5: 2007, Toronto, Proceedings... Toronto, 2007, p. 911-917.

PEDROSO EC, RIVARD B, CRÓSTA AP, SOUZA FILHO CR \& MIRANDA FP. 2001. Reconnaissance geologic mapping in the Tapajós Mineral Province, Brazilian Amazon, using spaceborne SAR imagery and airborne geophysics. Canadian Journal of Remote Sensing, 27(6): 669-678.

PEREGOVICHB, MATHIS A \& GOMES RSS. 2008. Transition from smallscale artisanal gold mining to large-scale corporate mining in the Tapajós Mineral Province, Brazil. In: Congr. Bras. Geol., 44., 2008, Curitiba. Anais... Curitiba: SBG, 2008, p. 188.

PIRES ACB. 1995. Identificação geofísica de áreas de alteração hidrotermal, Crixás-Guarinos, Goiás. Revista Brasileira de Geociências, 25(1): 61-68.

PORWAL A, CARRANZA EJM \& HALE M. 2003. Knowledge-driven and data-driven fuzzy models for predictive mineral potential mapping. Natural Resources Research, 12(1): 1-25.

RABUS B, EINEDER M, ROTH A \& BAMLER R. 2003. The Shuttle Radar Topography Mission - a new class of digital elevation models acquired by spaceborne radar. Journal of Photogrammetry \& Remote Sensing, 57 : 214-262.

RODRIGUES JL, BRAGA JBP, OLIVEIRA RAF \& DANIN T. 2008. Tapajós Mineral: um novo ciclo de oportunidades e domínios. In: Congr. Bras. Geol., 44., 2008, Curitiba. Anais... Curitiba: SBG, 2008, p. 187.

ROEST WR, VERHOEF J \& PILKINGTON M. 1992. Magnetic interpretation using 3-D analytic signal. Geophysics, 57: 116-125.

SANTOS JOS, HARTMANN LA, GAUDETTE HE, GROVES DI, McNAUGHTON NJ \& FLETCHER IR. 2000. A new understanding of the Provinces of the Amazon Craton based on integration of Field mapping and U-Pb and Sm-Nd geochronology. Gondwana Research, 3(4): 453-488.

SANTOS JOS, GROVES DI, HARTMANN LA, MOURA MA \& MCNAUGHTON NJ. 2001. Gold deposits of the Tapajós and Alta Floresta domains, Tapajós-Parima orogenic belt, Amazon Craton, Brazil. Mineralium Deposita, 36: 278-299. 
SANTOS JOS, VAN BREEMEN OB, GROVES DI, HARTMANN LA, ALMEIDA ME, McNAUGHTON NJ \& FLETCHER IR. 2004. Timing and evolution of multiple paleoproterozoic magmatic arcs in the Tapajós Domain, Amazon Craton: constraints from SHRIMP and TIMS zircon, baddeleyite and titanite U-Pb geochronology. Precambrian Research, 131: 73-109.

SANTOS JOS, HARTMANN LA, RIKER SR, SOUZA MM, ALMEIDA ME \& McNAUGHTON NJ. 2006. A compartimentação do Cráton Amazonas em províncias: avanços ocorridos no período 2000-2006. In: Simpósio de Geologia da Amazônia, 9., 2006, Belém. Anais... Belém: SBG, 2006, resumos expandidos. CD-ROM.

SILVA AAC. 2003. Processamento, interpretação e integração de dados geológicos e geofísicos da Província Mineral do Tapajós. Dissertação (Mestrado em Geologia) - Universidade de Brasília, Brasília-DF, 137 pp.

SILVA AM, TEIXEIRA AA, MCCAFFERTY A, PIRES ACB, MORAES RAV \& SOUZA FILHO CR. 2005. Mapping Archean Greenstone-Hosted Deposits with Probability Ratio and Weights of Evidence Models, Quadrilátero Ferrífero, Brazil. GIS and Spatial Analysis, Toronto, Canadá, vol. $1,551-556$

SILVA AAC, SILVA AM \& FUCK RA. 2007. Interpretação de dados aero- geofísicos da Província Mineral do Tapajós aplicada à geologia regional e prospecção de ouro. In: ROSA-COSTA LT, KLEIN EL, VIGLIO EP (Orgs.). Contribuições à Geologia da Amazônia. SBG-Núcleo Norte, Belém, vol. 5, 63-74.

TISSARI S, NYKÄNEN VM, LERSSI J \& KOLEHMAINEN M. 2007. Classification of soil groups using weights-of-evidence-method and RBFLNneural nets. Natural Resources Research, 16(2): 159-169.

VASQUEZ ML \& KLEIN EL (Orgs.). 2000. Projeto Especial Província Mineral do Tapajós (PROMIN-TAPAJÓS). Geologia e recursos minerais da Folha Rio Novo (SB.21-Z-C), Estados do Amazonas e Pará. Escala 1:250.000. Brasília, CPRM, 45 pp.

VASQUEZ ML, RICCI PSF \& KLEIN EL. 2002. Granitóides pós-colisionais da porção leste da Província Tapajós. In: KLEIN EL, VASQUEZ ML \& ROSA-COSTA LT (Eds.). Contribuições à geologia da Amazônia. SBGNúcleo Norte, Belém, vol. 3,67-83.

VELOSO ASR, SANTOS MD, SANTOS WP \& SNEE LW. 2008. Relação entre a mineralização aurífera do depósito Ouro Roxo e a zona de cisaIhamento Ouro Roxo-Cantagalo, Província Tapajós, Pará. In: Congr. Bras. Geol., 44., 2008, Curitiba. Anais... Curitiba: SBG, 2008, p. 169.

\section{NOTAS SOBRE OS AUTORES}

Thais Andressa Carrino. Geóloga (UNICAMP, 2007) e Mestre em Geologia (UnB, 2010). Suas áreas de interesse são: processamento e interpretação de imagens de sensoriamento remoto multiespectral, SAR, e aerogeofísicas; geoestatística, sistemas de informações georreferenciadas; e modelagens de dados espaciais com foco em exploração de recursos naturais.

Adalene Moreira Silva. Engenheira Geóloga (1989) graduada pela Universidade Federal de Ouro Preto, Mestre (1992) e Doutora em Geologia (1999) pela Universidade de Brasília. Profissionalmente, atuou como pesquisadora do Serviço Geológico Americano (1997-1999), Professora Visitante da Universidade de Brasília (2000-2002), Pesquisadora (05/2002-04/2003) e Professora do Instituto de Geociências da UNICAMP (04/2003-10/2005). Atualmente, é Professora e Coordenadora de Extensão do Instituto de Geociências da Universidade de Brasília e Professora Colaboradora Voluntária do Instituto de Geociências da UNICAMP. Desenvolve projetos sobre novas técnicas de processamento, interpretação e integração de dados aplicados à exploração mineral, hidrogeologia e ambiente.

Nilson Francisquini Botelho. Possui graduação em Geologia pela Universidade de Brasília (1981), mestrado em Geologia pela Universidade de Brasília (1984) e doutorado em Geologia - Université de Paris VI (Pierre et Marie Curie, 1992). Atualmente é Professor Titular da Universidade de Brasília. Tem experiência na área de Geociências, com ênfase em Mineralogia, Petrologia e Metalogenia, atuando principalmente nos seguintes temas: granito, alteração hidrotermal, ouro, cobre, estanho e outros metais raros. Desenvolve projetos de pesquisa nos estados de Goiás, Tocantins e Amazonas e nas províncias minerais de Carajás e do Tapajós.

Alexandre Augusto Cardoso da Silva. Geólogo (2000) e Mestre (2003) pela Universidade de Brasília com ênfase, neste último, em geologia regional e prospecção de ouro utilizando dados magnéticos e gamaespectrométricos. Trabalha como geofísico na Petróleo Brasileiro S.A. desde 2002, principalmente na área de inversão sísmica e sísmica 4D. 